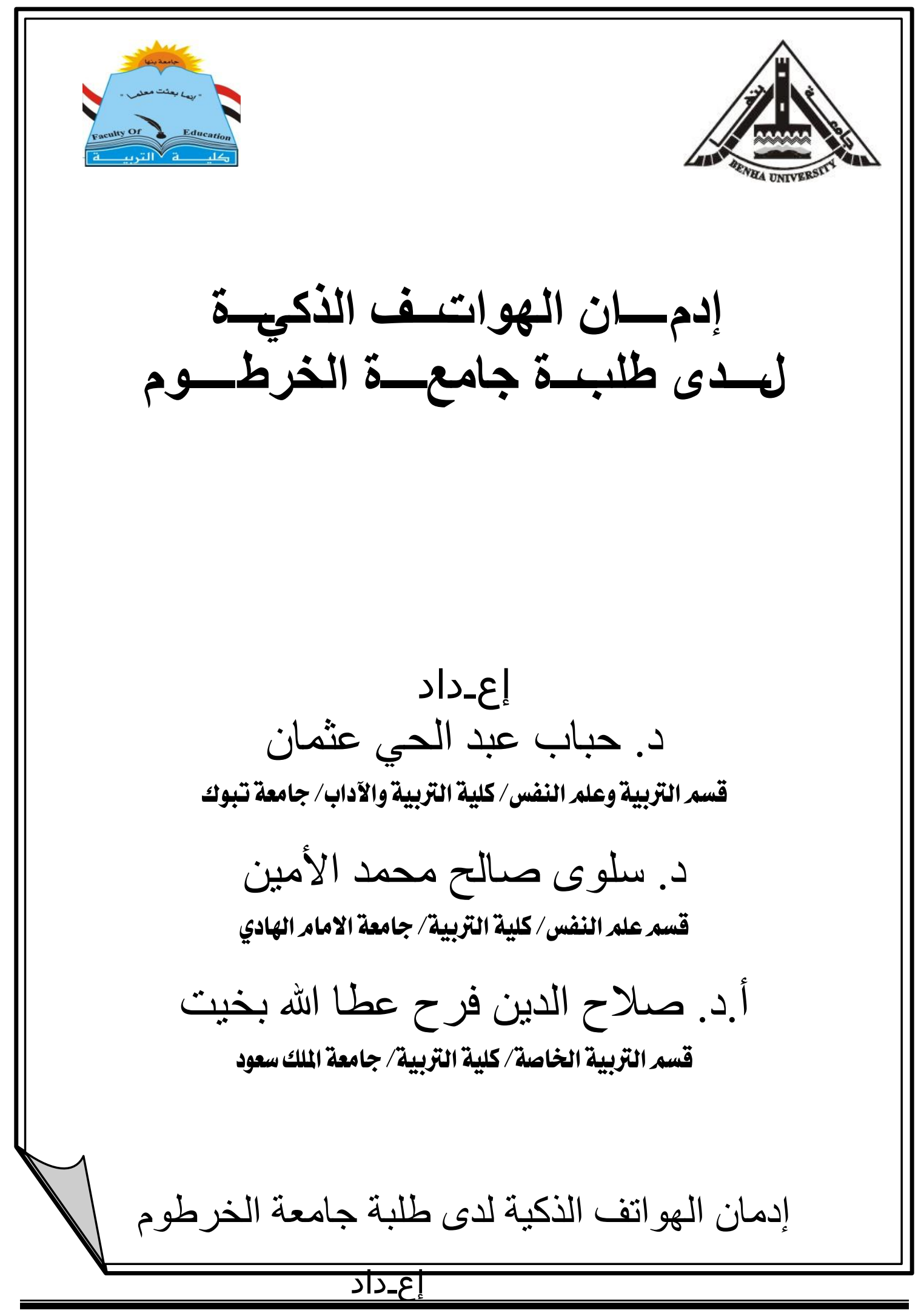




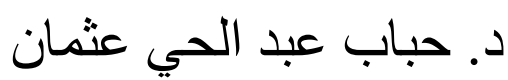

قسم التربية وعلد النضس / كلية التربية والآداب/ جامعة تبوك

د. سلوى صالح محمد الأمين

قسم عله النضس/كلية التزبية/ جامعة الاماه الهادي

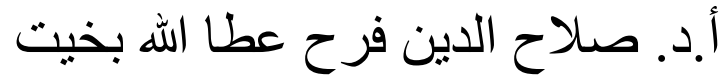

قسم التربية الخاصة/ كلية التربية/ جامعة الملك سعود الدان

\section{الملخص الإنرن}

كثفت التقارير أن الإدمان على الإنترنت والهواتف الذكي مة هو قضية صحة نفسية

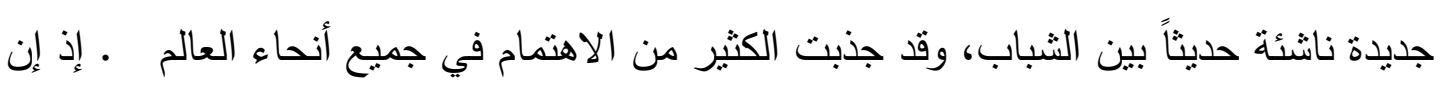

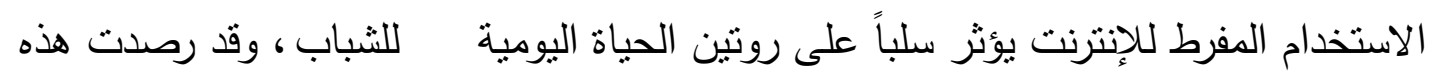

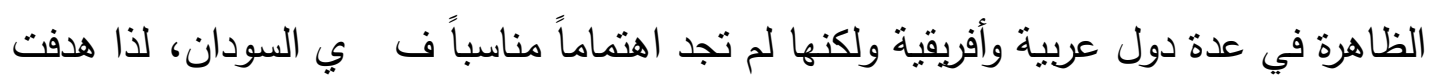

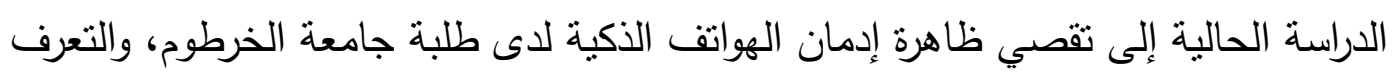

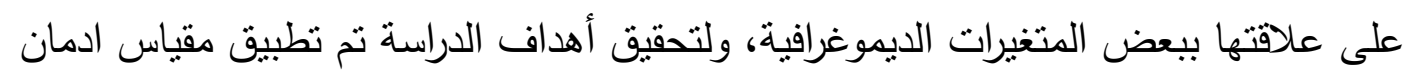

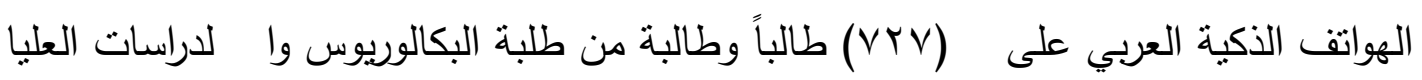

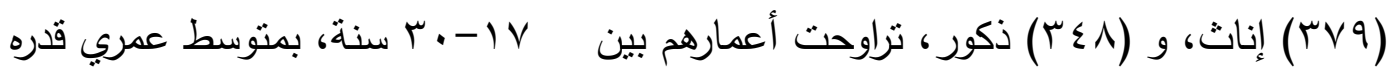
(Y I IV) تبلغ (39.2\%)، وأنه لا نوجد فروق بين الذكور والاناث ، وعدم وجود علاقة ارتباطية بين

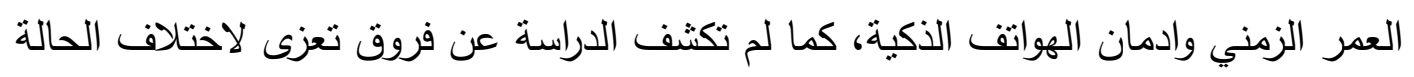

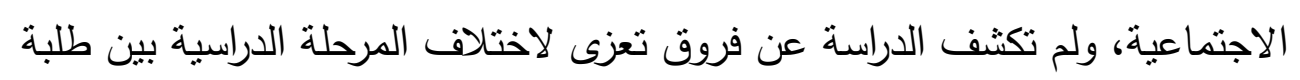

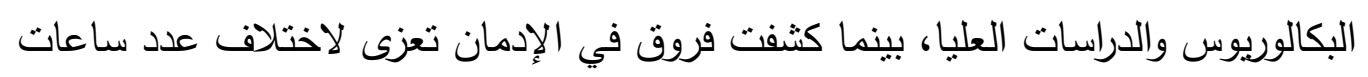

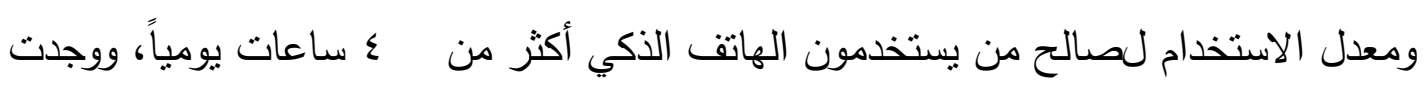
فروق تعزى لاختلاف التخصص بين الأدبيين والعلميين لصالح الأدبيين.

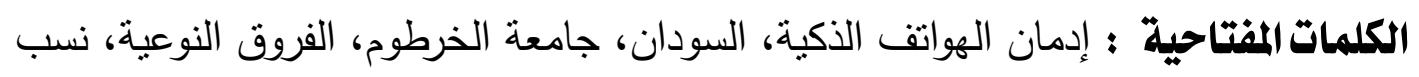

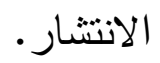

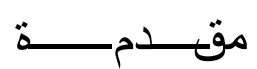

تعد ظاهرة ادمان الهواتف الذكية من المشكلات المعاصرة الأكثر تزايداً، وقد وجدت

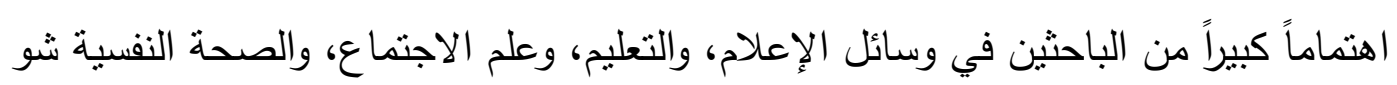


إدمان الهو اتف الذكية لدى طلبن

جامعة الخر طوم لأن

وكوو وكيم (Choi, Koo, \& Kim, 2015)، وقد بدأت الدراسات عن ظاهرة إدمان الانترنت منذ منتصف تسعينات القرن الماض عي علي يد يونغ (Young,1996) حيث تم تصنيفها كاضطراب اكلينيكي، وتم الاعتماد على المعايير التشخيصية للإدمان على الهاتق الذكي وإساءة استخدامه بناء على معايير إساءة استخدام المواد، ومعايير المقامرة وفق الدليل

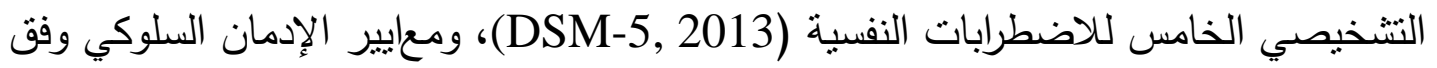
معايير قودمان (Goodman, 1990) وقريفيث (Griffiths, 2000). ولا تزال الدراسات المسحية تسجل مزيد من التفشي لهذه الظاهرة، وتثبر إحصاءات حديثة إلى أن ظاهرة إدمان

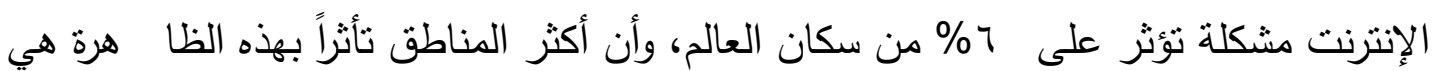

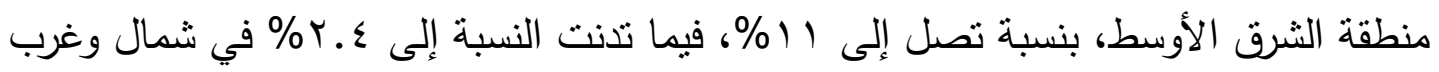

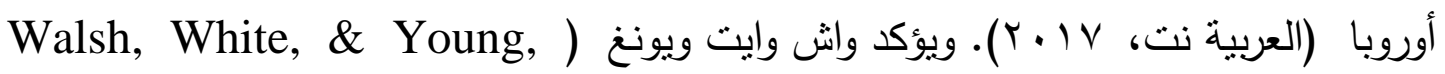

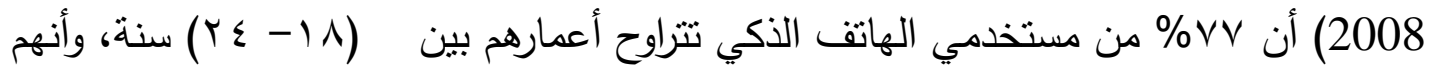
يحملون هواتفهم في كل مك ان تقريبا، حيث يكون الهاتف في منتاول أيديهم، وأنهم يتفقدون

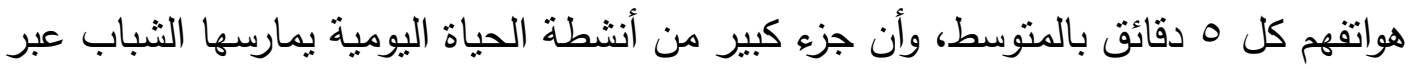

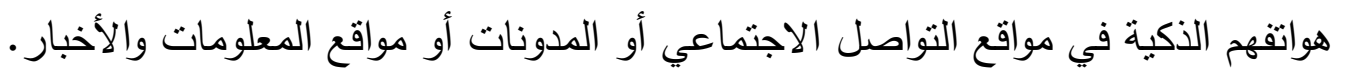

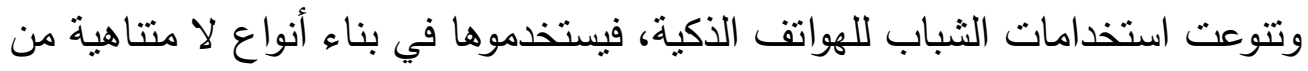

العلاقات الاجتماعية التي لا تثقيد بالضوابط الاجتماعية والدينية والسياسية، وتتميز هذه

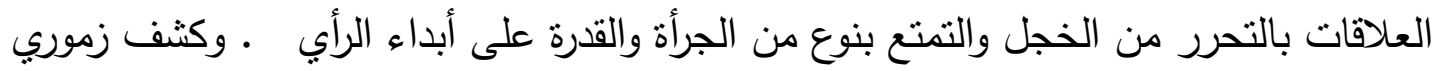

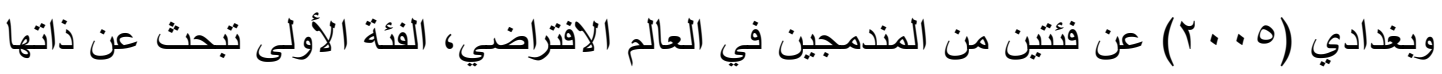
في عالم الافتراضية لتحققها بعيدا عن ضغوط المجتمع وتقاليده التي تكبح جماح مشاعرها وبالتالي يعتبر العالم الافتراضي بالنسبة لها هروب من سلطة المجتمع وتقاليده، أما الفئة الثانية فهي أيضا مندمجة في العالم الافتراضي ولكنها تحاول أن تتحدى سلطة التقاليد والقيم وتتجاوزها

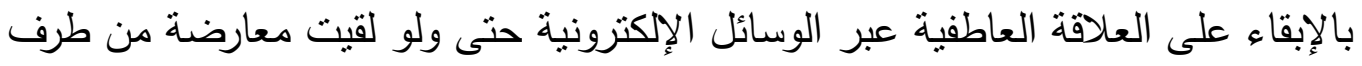

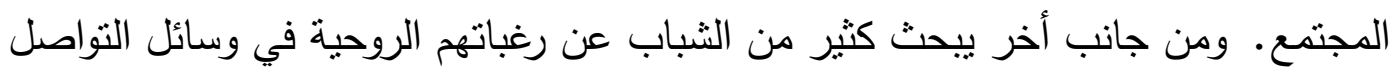

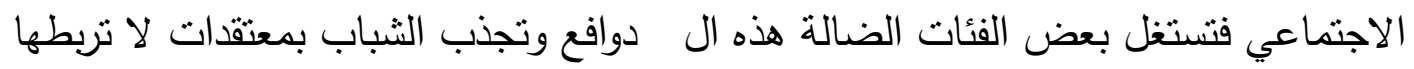
بالدين صلة، وكذلك بالنسبة لنكوين جماعات سياسية مختلفة والمشاركة السياسية، فقد استخدم الثباب الأنترنت في إثعال ثورات أسقطت أنظمة سياسية، بجانب استخدام الهواتف في نشر 
المعلومات والثائعات والإعلانات الصادقة والكاذبة (التميمي، (1 • ب). وتعدد دوافع الثباب في

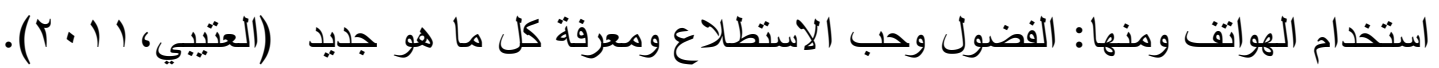

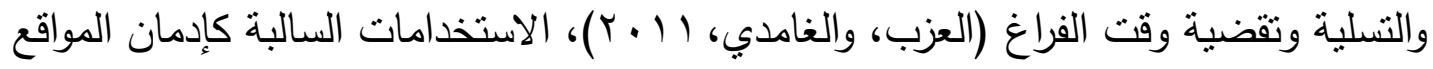

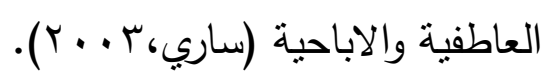

وتتمنل خطورة إدمان الهوا تف الذكية على الجوانب النفسية لدى طلبة الجامعات في جوانب عديدة، حيث لوحظ أن الاضطرابات النفسية والسلوكيات الثناذة لدى المراهقين ترتبط به بدرجة عالية (Kim, Lee, \& Lim, 2017)، وأن له تأثثر سلبي على النواصل الاجتماعي الني

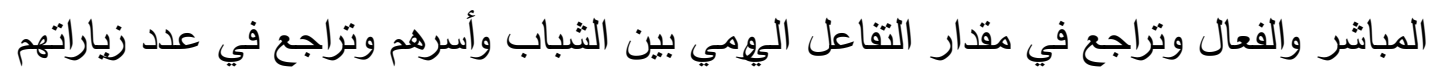
لأقاربهم، وانجاز المهام العملية، والذكاء العاطفي، والإجهاد الاجتماعي، والتتظيم الذاني، كما

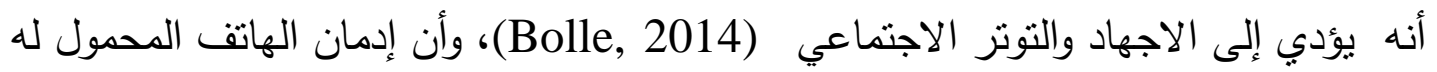

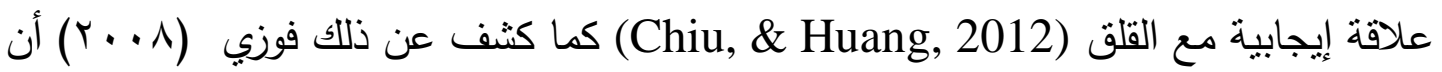

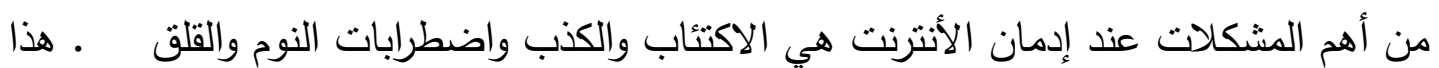
بالإضافة لتأثيره السلبي على الجوانب الأكاديمية لدى طلبة الجامعة، والذي رصدته عدة الأن الداب

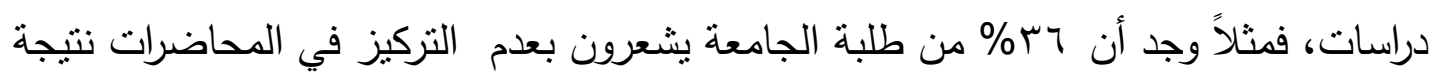

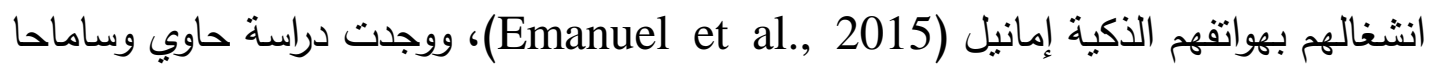
أدلة قوية على التأثير السلبي لإدمان الهاتف الذكي على (Hawi \& Samaha, 2016)

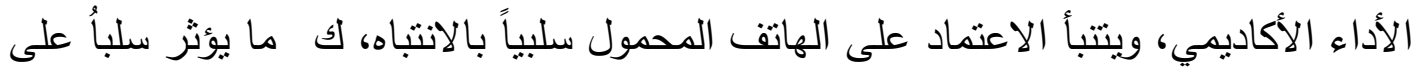

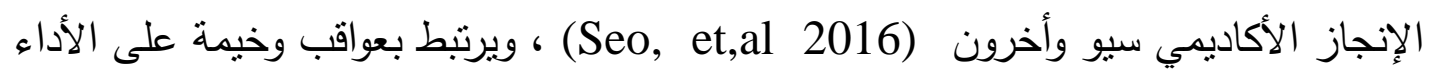

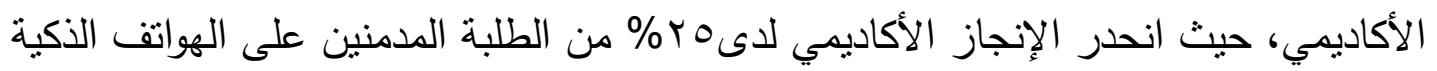

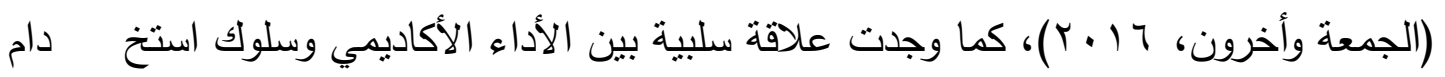
الهاتف الذكي، وأن الوقت المستغرق في استخدام الهاتف الذكي ينتبأ بالأداء الأكاديمي أوفادي الأبلاي

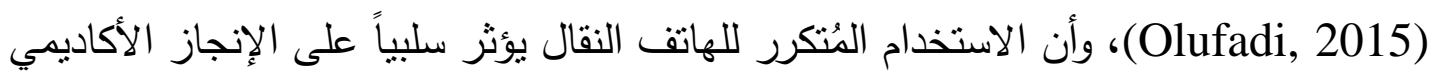

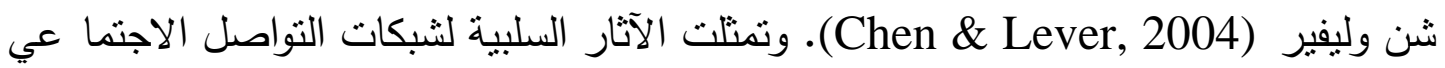

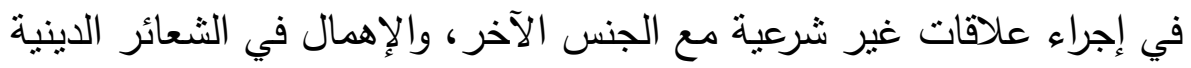

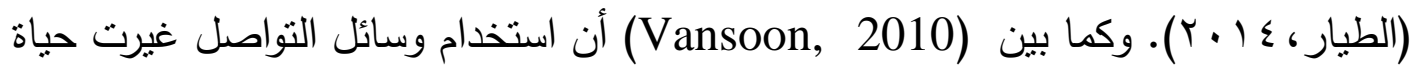

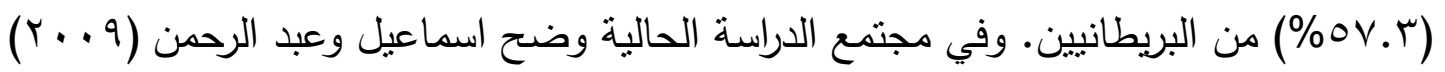


إدمان الهو اتف الذكية لدى طلبا جامعة الخرطوم لألفي

أن الثباب السوداني هم الفئة الأكثر استخدام للأنترنت في المجتمع السوداني، وأن للإنترنت آنار صحية ونفسية واجتماعية وأخلاقية وتربوية وتعليمية وثقافية واقتصادية.

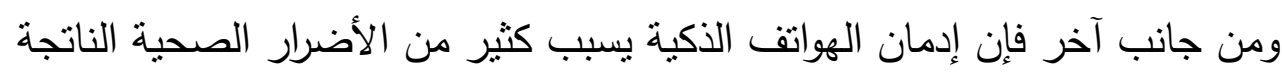

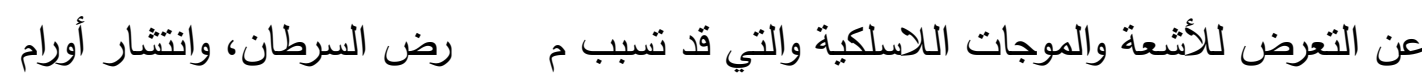

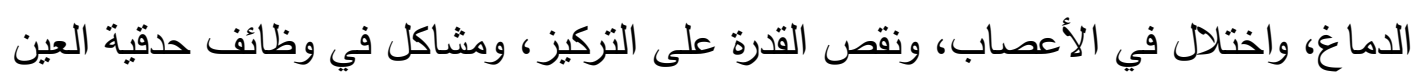

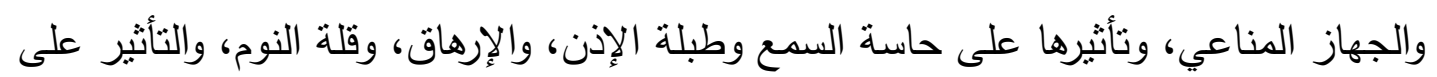
رسغ اليدين، وأوجاع في الرقبة والمفاصل (Alasdair \& Philips, 2011). الإطار النظري و الدراسات السابقة لقد حظي الإدمان بمفهومه العيادي بكثبر من الدراسات والبحوث بينما مازال

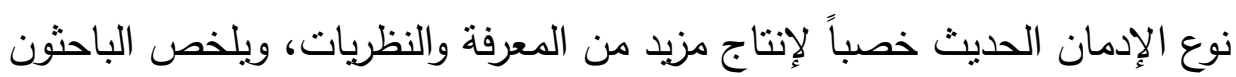

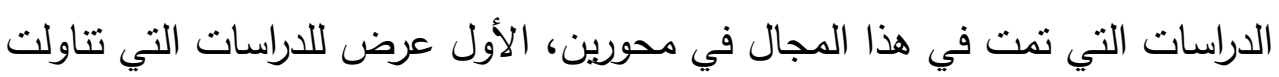

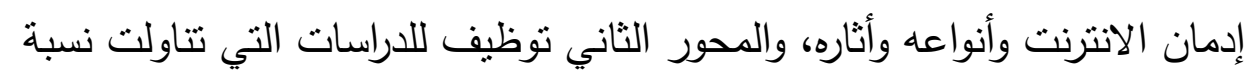
الانتشار والمتغيرات الديموغرافية في جزئية مناقثة النتائج.

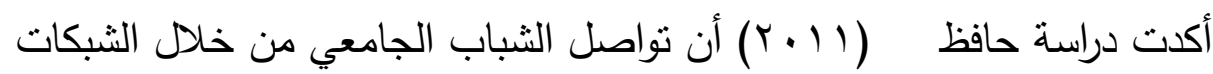

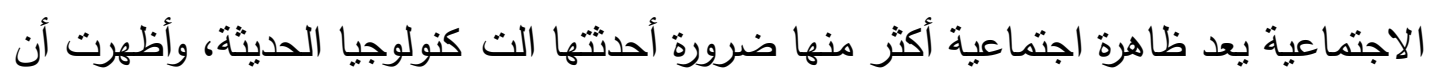
إدمان الفئة الثبابية على الاستخدام المفرط للشبكات الاجتماعية، أدى إلى فقدان المهارات

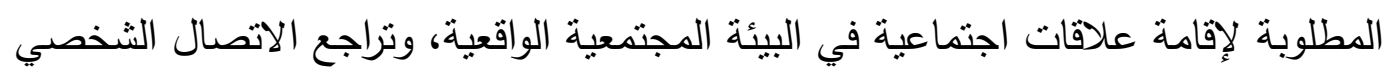

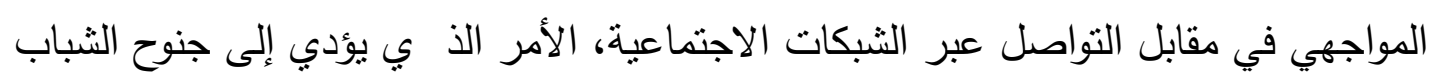

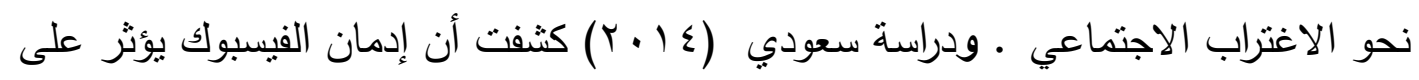
التوافق الأسري علي الطالب الجامعي.

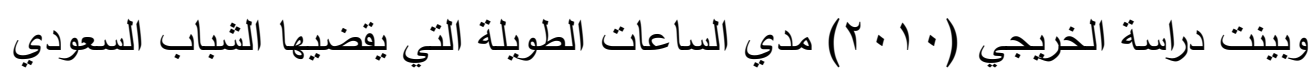

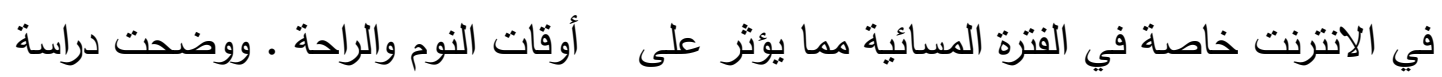

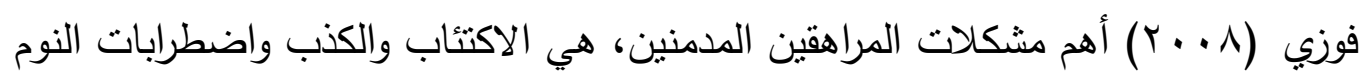

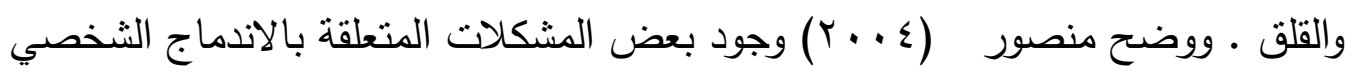
والاجتماعي لمدمني الانترنت. 
اهتمت دراسة خضر (9 . . ب) بقياس التأثثرات الثقافية والنفسية والاجتماعية لاستخدام

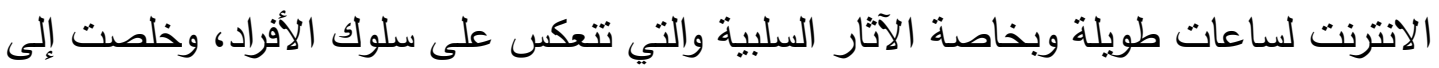

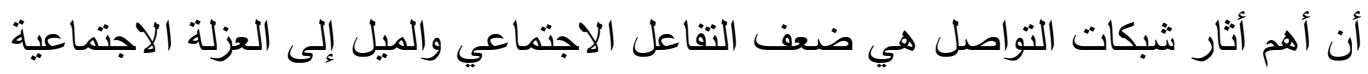

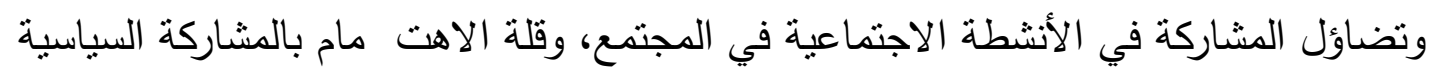
ومدى انعكاس ذللك على الصحة النفسية للأفراد وشعورهم بالوحدة والملل والاكتئاب والقلق.

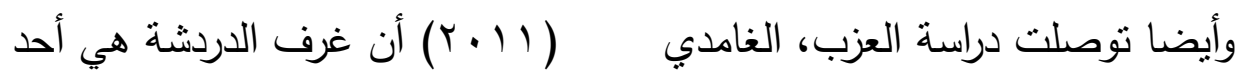

r

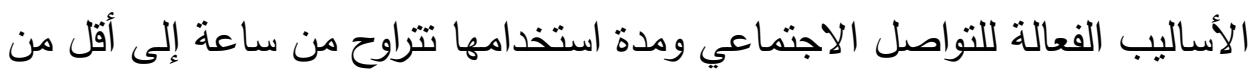

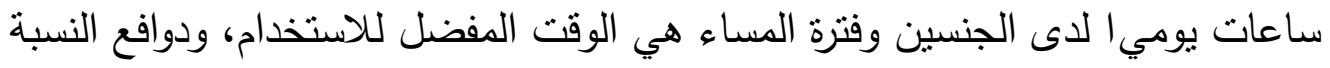

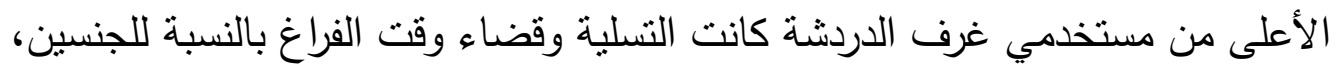

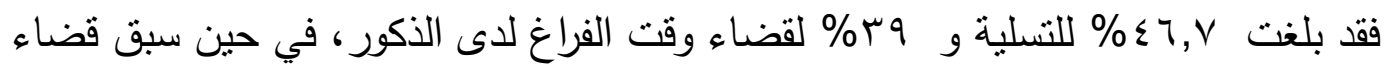

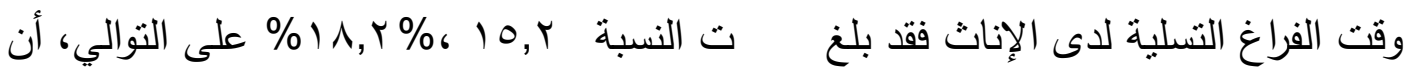

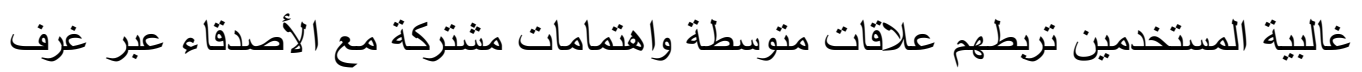
الدردشة، وغالبيتهم يضطرون إلى عدم قول الحقيقة ولديهم اتجاه نحو الجرأة في الحوارات

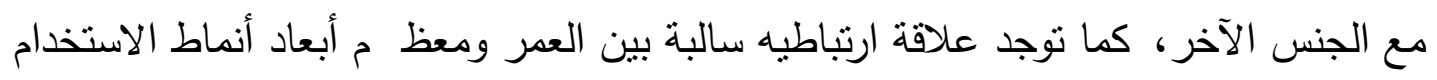

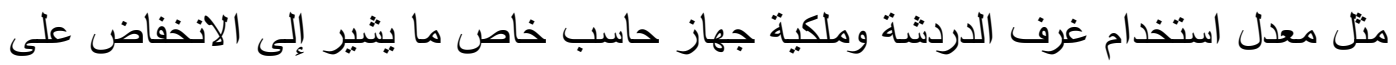

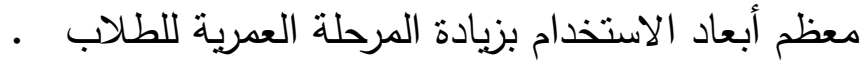

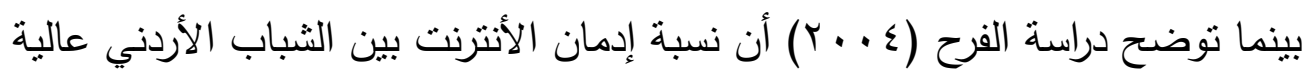

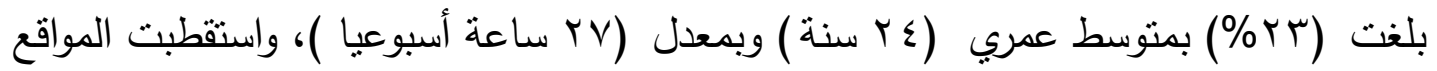

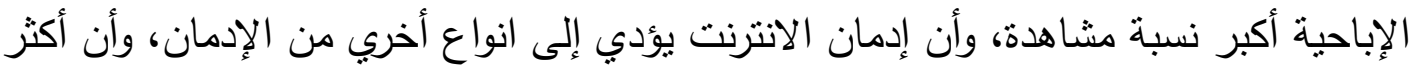

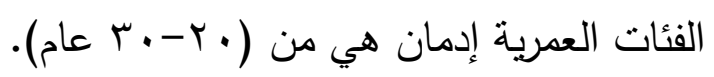

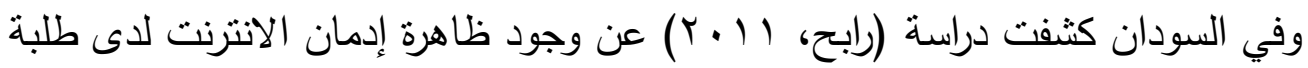

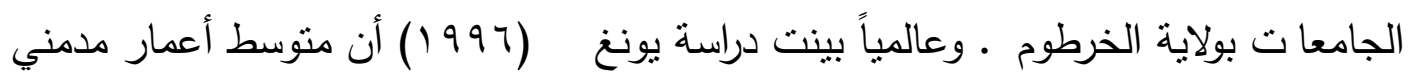

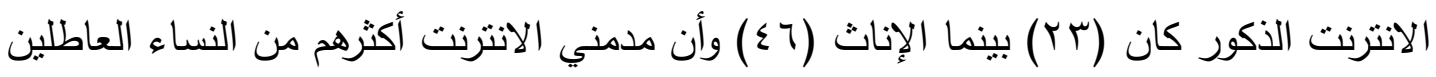

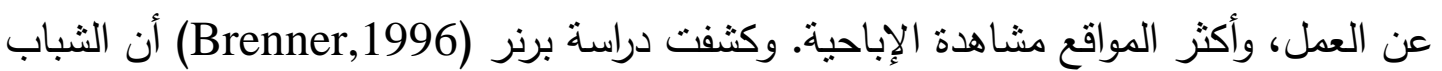

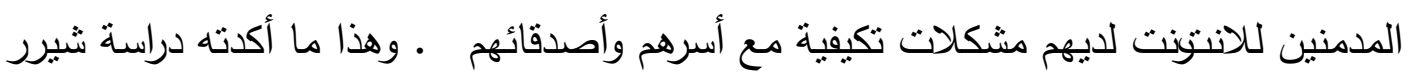
(scherer,1997) 
إدمان الهو اتف الذكية لاى طلبا

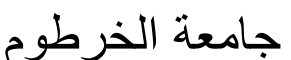

والاجتماعي للطلبة . وتتاول يونغ ورودجرز (Young \&Rodgers, 1998b) في دراستهر

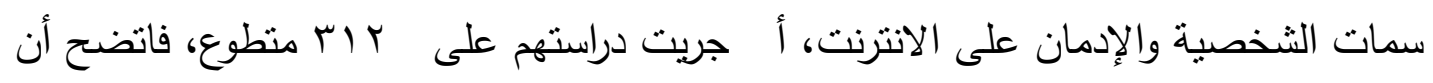

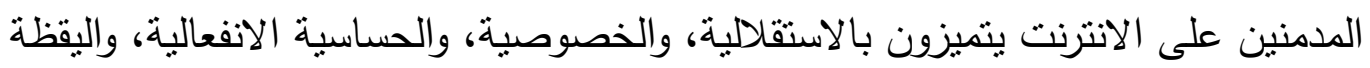
والحذر، والانغلاق على الذات. وبحثت دراسة تسي ولين (Tsai \& Lin, 2001) في اتجاهات

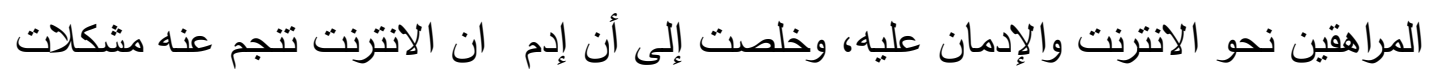

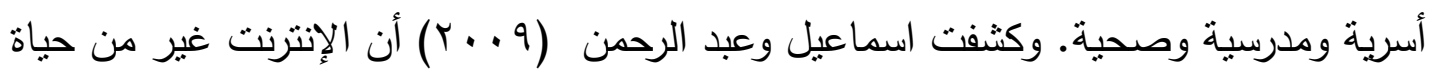

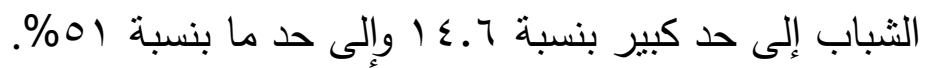
مشكلــة الــدر اسبــة إدمان التكنلوجيا تخطى حاجز تتاول العقاقير أو نحوها أنه أكثر خطورة وقوة وسرعة

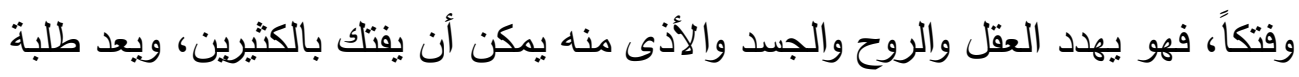

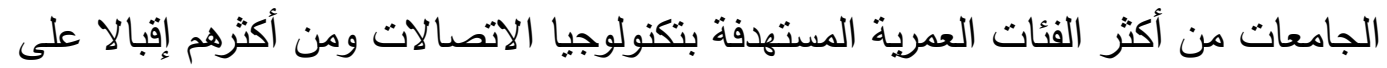
اقتتاء واستخدام الهواتق الذكية، حيث يقضون جزءٌ كبير من وقتهم في استخدامه، والانشغال

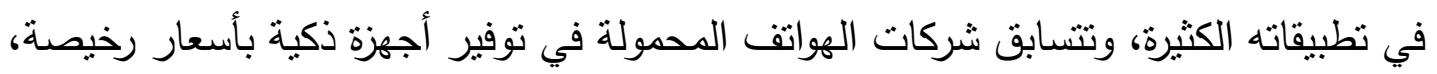

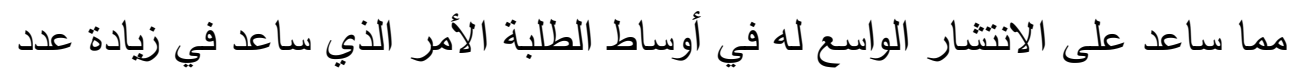

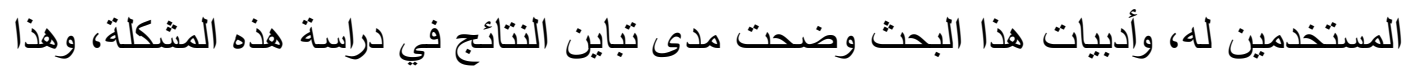
ما حدا بفويق البحث نحو توجيه بحثهم في هذا المجال الخصب، وسعوا للتعرف على هذه

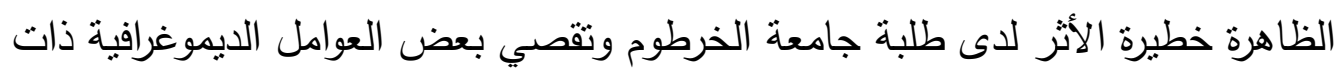
العلاقة بها. وطرحوا التساؤلات التالية:

ا ما نسبة انتشار إدمان الهواتف الذكية لاى طلبة جامعة الخرطوم؟

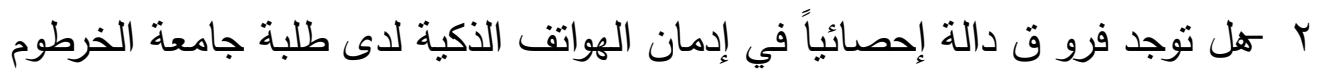

$$
\text { تعزى لاختلاف الجنس (ذكور / إناث)؟ }
$$

r هل توجد علاقة ارتباطية ذات دلالة إحصائية بين العمر الزمني وادمان الهواتق الذكية

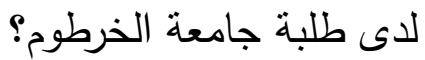




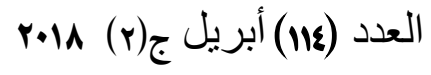

مجلة كلية التربية ببنها

ع هل توجد فروق دالة إحصائياً في إدمان الهواتف الذكية لدى طلبة جامعة الخرطوم

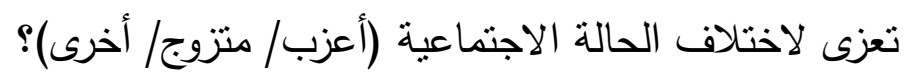

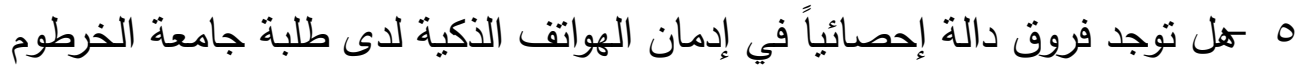

$$
\text { تعزى لاختلاف المرحلة الدراسية (بكالوريوس/ دراسات عليا)؟ }
$$

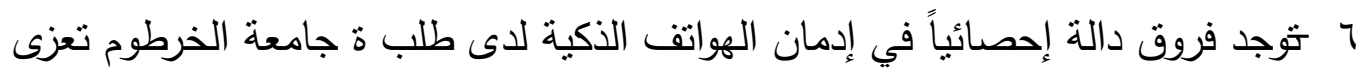

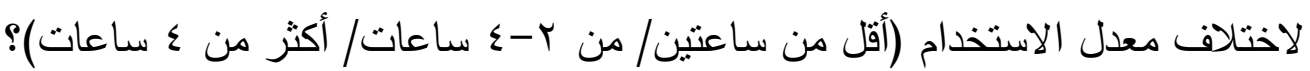

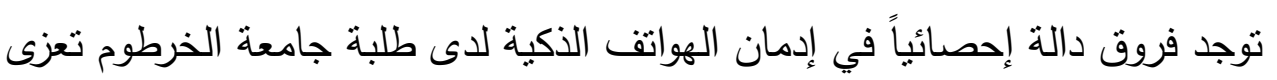

$$
\begin{aligned}
& \text { لاختلاف التخصص (علمي/ أدبي)؟ } \\
& \text { أه ـــداف الـــدر اســـــة }
\end{aligned}
$$

تهذف الدراسة إلى التعرف على نسبة انتشار إدمان الهواتف الذكية لدى طلبة جامعة الخرطوم، والفروق الجنسية في إدمان الهواتق الذكبة لدى طلبة الجامعة، والعلاقة بين العمر

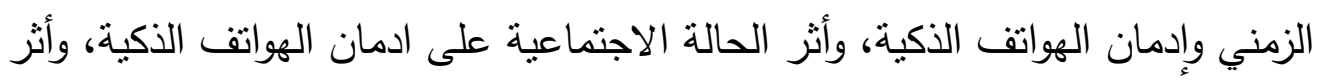

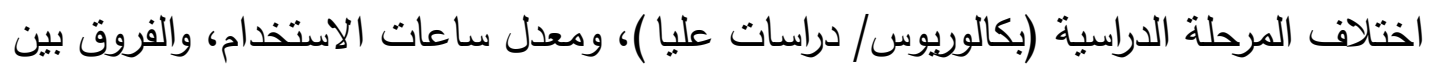
الادبيين والعلميين.

$$
\text { أهميــة الكدر استــــة }
$$

I وضع لبنة أساسية في الدراسات التطبيقية لهذه الظاهرة الحديثة من خلال توفير معلومات

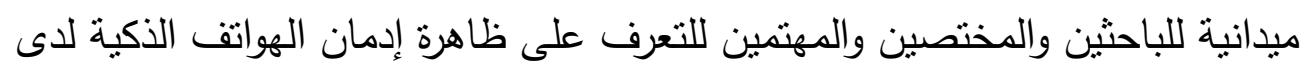

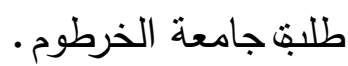

r +لاسهام في مساعدة الطلبة في مجال الإرشاد والعلاج النفسي وذلك من خلال ايضاح خصائص هذه الفئة -مدمني الهواتف الذكية - وعلاقتها ببعض المتغيرات، مما بسهم في معالجتهم وفي فهم أكثر لددمني الهواتق الذكية. r كما قد تسهم الدراسة في مساعدة المختصين في المجالات النفسية في التعرف على مدى انتشار إدمان الهواتق الذكية لدى فئة طلبة جامعة الخرطوم مما في يساعدهم في وضع خطط وقائية وعلاجية مناسبة تقوم على التوجيه والتتقيف للاستخدام المناسب والايجابي للهاتق الذكي. 
إدمان الهو اتف الذكية لاى طلبا

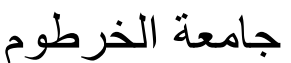

$$
\text { مصطلحسـات الـدر اســـة: }
$$

إدمان الهواتف الذكية

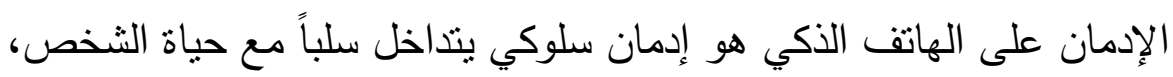

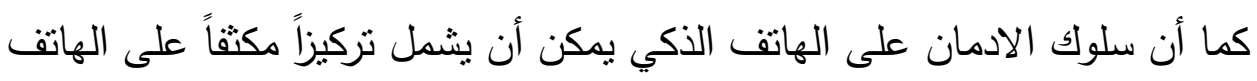

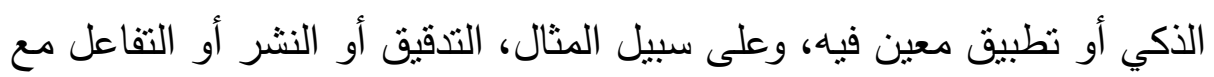

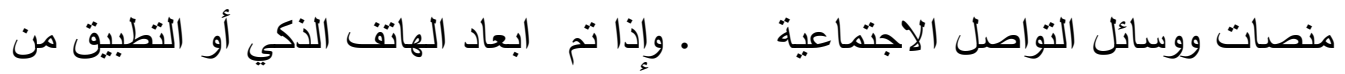

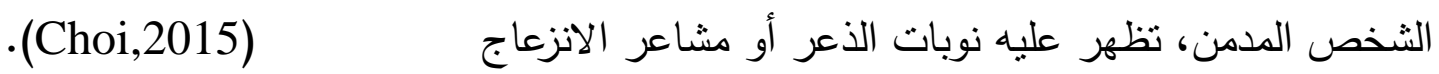

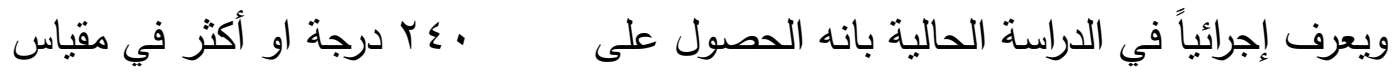
ادمان الهواتق الذكية العربي المستخدم في الدراسة الحالية.

$$
\text { حسلدود الكدر استـة }
$$

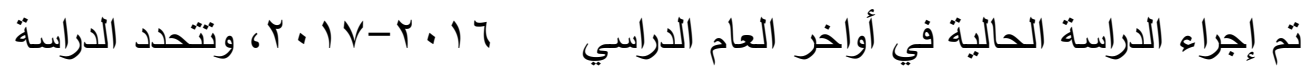

بالعينة التي طبق عليها المقياس، وبالمقياس المستخدم في الدراسة.

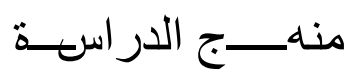

المنهج الوصفي التحليلي المقارن.

$$
\text { مجتمع الــدر اسـة }
$$

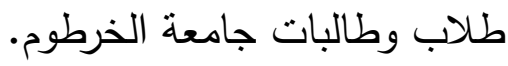

$$
\text { عينــــة الـدر اســة }
$$

استخدمت الطريقة الطبقية والعشوائية لاختيار الطلاب، وتم تقسيم المجتمع إلى طبقتين

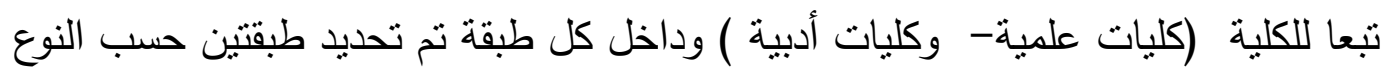
(ذكور - إناث) وداخل كل طبقة تحديد طبقتين تبعا للمستوي الدراسي (بكالوريوس - دراسات

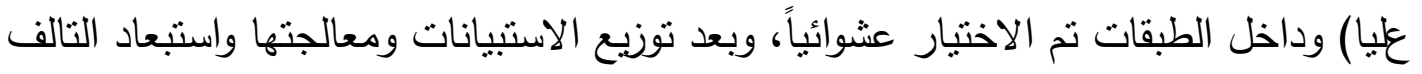

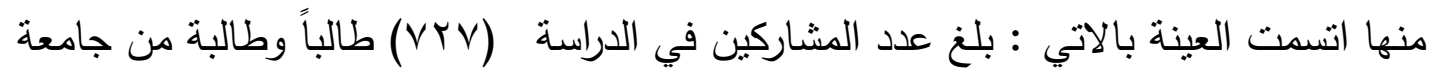

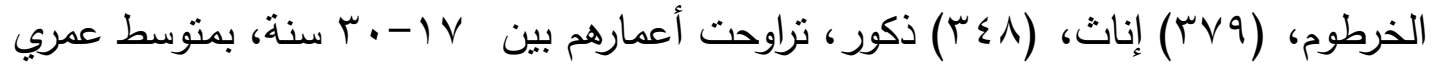

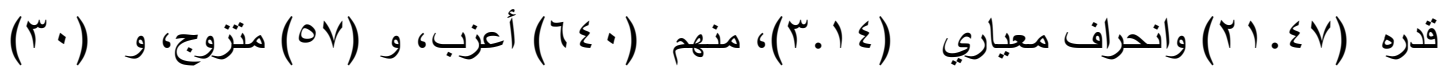

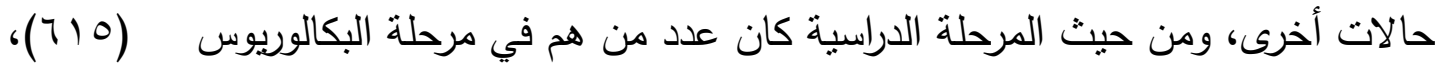


و (Y I ( ) دراسات عليا، من كليات علمية وادبية مثل : الآداب، والقانون، الهندسة، العلوم، الطب، الصيدلة، الاقتصاد، العل وم الرياضية، إدارة الاعمال، وعموما الأدبيين بلغ عددهم

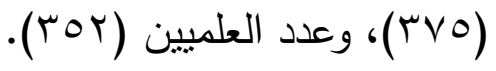

أداة الكدر اســــة

استخدم في الدراسة الحالية مقياس ادمان الهواتق الذكية الذي نم إعداده في دراسة

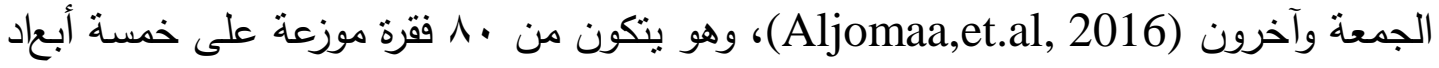

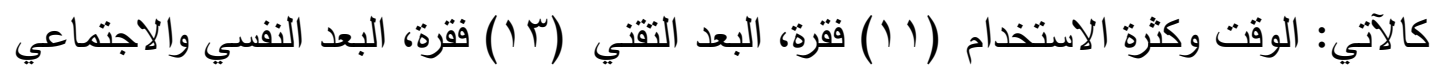

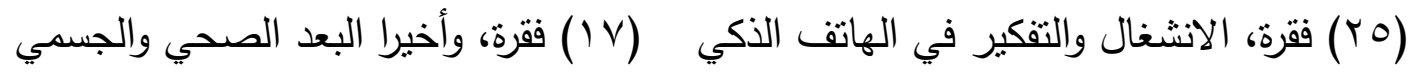
( ) ( ) ( )

تم التحقق من صدق البناء الداخلي للمقياس، وذلك بقياس معاملات الارتباط بين فقرات

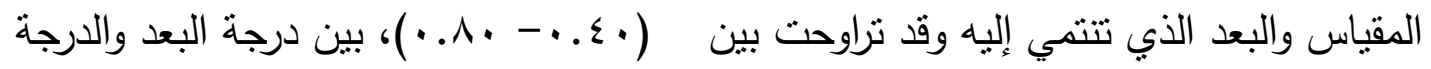

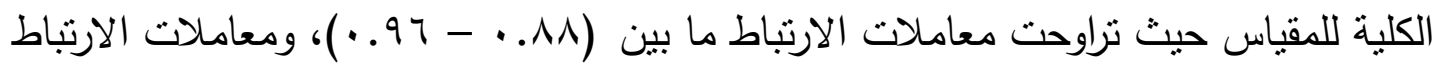

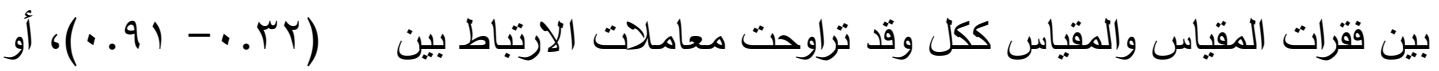

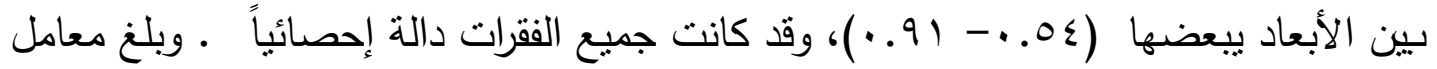

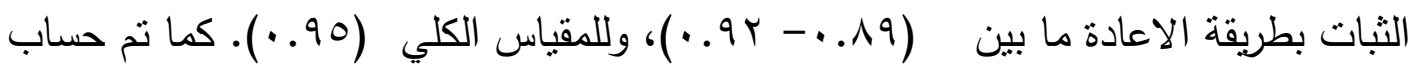

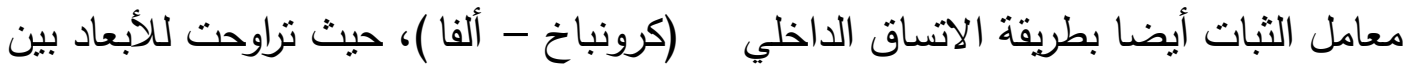

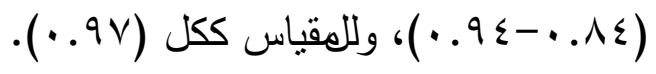

وللتحقق من الصدق والثبات في البيئة السودانية نم تطبيق المقياس على عينة

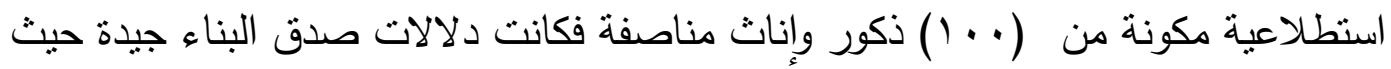
كانت ارتباطات الفقرات بأبعادها دالة عند مستوى ا ... و ه...، وكذلك كانت الارتباطات بين

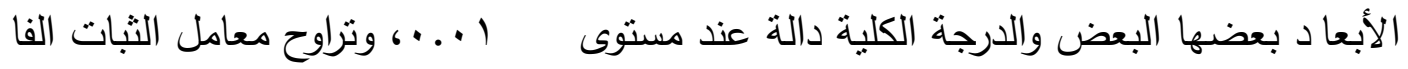

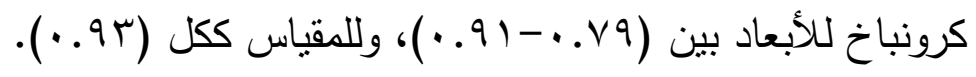
تحليــلـل بيانــــات الدر اســــة تم ترميز وإدخال البيانات واستخدام المعالجات الإحصائية باستخدام برنامج IBM SPSS Statistics 24 التكرارات والنسبة المئوية، وللسؤال الثاني اختبار (ت) لعينتين مستقلتين غير مرتبطنين، 
إدمان الهو اتف الذكية لاى طلبا

جامعة الخرطوم لألفي

وللسؤال الثالث معامل ارتباط بيرسون، وللسؤال الرابع تحليل التباين الأحادي، وللسؤال الخامس اختبار (ت) لعينتين مستقلتين غير مرتبطتين، وللسؤال السادس تحليل التباين الأحادي واختبار الحيل شيفيه، وللسؤال السابع اختبار (ت) لعينتين مستقلتين غير مرتبطتين.

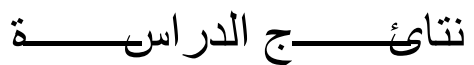

\section{نتيجة السؤال الأول : ما نسبة انتشار إدمان الهواتف الذكية لدى طلبة جامعة الخرطوه :}

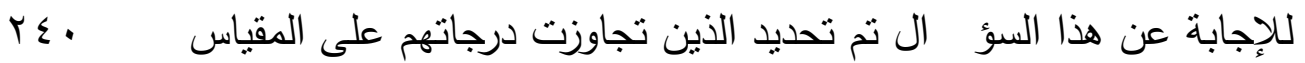
درجة وهي درجة القطع المحدة في المقياس، ثم تم إيجاد التكرارات والنسبة المئوية،

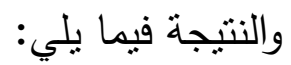

جدول (1) نسب انتشار الإدمان للدى طلبة جامعة الخرطوم

\begin{tabular}{|c|c|c|}
\hline النسبة المئوية & التكرار & التصنيف \\
\hline$r q, r q$ & ras & مدمن \\
\hline $9 \cdot, \wedge \in$ & «\&! & غير ملدمن \\
\hline $1 \cdots,+\infty$ & vrr $\square$ & المجموع \\
\hline
\end{tabular}

يوضح جدول ( (1) أن نسبة انتشار إدمان الهواتف الذكية لدى عينة الدراسة (39.2\%).

نتيجة السؤال الثاني : ما الفروق النوعية في إدمان الهواتف الذكية للى طلبة جامعة الخرطوم : للإجابة عن هذا السؤال تم تطبيق اختبار (ت) لعينتين مستقلتين غير مرتبطنين، ونتيجة هذا الاجراء موضحة فيما يأني:

جلدول (r) الفروق الجنسية في ادمان الهواتف الذكية

\begin{tabular}{|c|c|c|c|c|c|c|}
\hline الاحتمالية & قيمةت & الحرية & الالنحراف & الحسابي & العلد & الجنس \\
\hline \multirow{2}{*}{ arld] } & \multirow{2}{*}{.99.} & \multirow{2}{*}{ rro } & $ه\{\varepsilon T \square$ & $\left.r r_{0}, r_{A}\right]$ & $\left.{ }_{P} \leqslant \backslash\right]$ & ذكر \\
\hline & & & $7 \xi, \Delta r \square$ & $M \mid q, \wedge \varepsilon \square$ & rva & أنثى \\
\hline
\end{tabular}

يوضح جدول (r) عدم وجود فروق ذات دلالة إحصائية بين الذكور والإناث، حيث أن قيمة (ت) بلغت (ب99.) وهي قيمة غير دالة إحصائياً. 
نتيجة السؤال الثالث : العلاقة الارتباطية بين العمر الزمني وإدمان الهواتف الذكية لدى طلبة

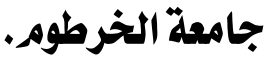

للإجابة عن هذا السؤال تم تطبيق اختبار معامل ارتباط بيرسون، فبلغ معامل الارتباط بين العمر وادمان الهواتف الذكية (072.-) وهو معامل غير دال إحصائياً . وبذا تكون نتيجة هذا السؤال عدم وجود علاق ارتباطية بين العمر الزمني وإدمان الهواتف الذكية لاى طلبة

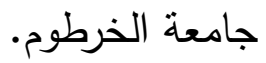

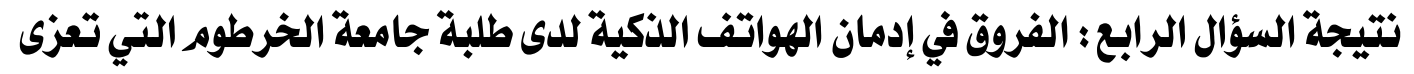
لاختلاف الحالة الاجتماعية (أعزب/ متزوج/ أخرى) :

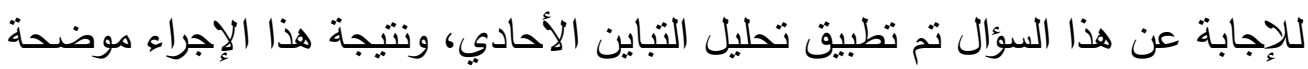
كما يأني: جدول (ז) نتائج تحليل التباين الأحادي للفروق في إدمان الهواتف الذكية حسر الحالة الاجتماعية

\begin{tabular}{|c|c|c|c|c|c|}
\hline القيمة الاحتمالية & قيمة ف & متوسط المربعات & درجات الحرية & مجموع المربعات & مصلدر التباين \\
\hline \multirow{3}{*}{$79 .}$. & \multirow{3}{*}{$\$ 10}$. & I\&vv, rqv $\square$ & $r \square$ & r90s, V90 & بيز المجمومات \\
\hline & & rooq, OV\& $\square$ & VYE & rorrirI,EYr & داخل المجموعات \\
\hline & & & vry & 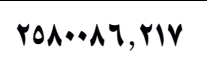 & الكلي \\
\hline
\end{tabular}

يوضح جدول (r) عدم وجود فروق ذات دلالة إح صائية حسب الحالة الاجتماعية (أعزب/متزوج/ أخرى)، حيث أن قيمة (ف) بلغت (0.415) وهي قيمة غير دالة إحصائياً.

نتيجة السؤال الخامس : الفروق في إدمان الهواتف الذكية لدى طلبة جامعة الخرطوم التي تعزى لاختلاف المرحلة الدراسية (بكالوريوس/ دراسات عليا) : للإجابة عن هذا السؤال تم تطبيق اختبار (ت) لعينتنين مستقلتين غير مرتبطتين، ونتيجة هذا الاجراء موضحة أدناه:

جلدول (§) يوضح الفروق في ادمان الهواتف الذكية حسب المرحلة الدراسية

\begin{tabular}{|c|c|c|c|c|c|c|}
\hline القيمة الاحتمالية & قيمة ت & درجات الحرية & الانحراف المعياري & المتوسط الحسابي & العدد & الجنس \\
\hline \multirow{2}{*}{.94[} & \multirow{2}{*}{ 1,7^r } & \multirow{2}{*}{ rro } & $\Delta \wedge, 1]$ & rYI, T\&] & $910 \square$ & بكالوريوس \\
\hline & & & $T \xi, r \square$ & 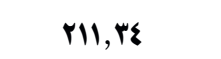 & $11 r \square$ & دراسات عليا \\
\hline
\end{tabular}


إدمان الهو اتف الذكية لاى طلبا

جامعة الخرطوم لألفي

يوضح جدول (ع) عدم وجود فروق ذات دلالة إحصائية بين طلبة البكالوريوس وطلبة

الدراسات العليا في إدمان الهواتف الذكية، حيث بلغت قيمة (ت) (1.683) وهي قيمة غير دالة إحصائياً.

نتيجة السؤال السادس : الفروق في إدمان الهواتف الذكية للى طلبة جامعة الخرطور تعزى لاختلاف ساعات ومعدل الاستخدام :

للإجابة عن هذا السؤال تم تطبيق تحليل التباين الأحادي، ونتيجة هذا الإجراء موضحة كما يلي: جلدول (ه) تحليل التباين الأحادي للفروق في إدمان الهواتف الذكية حسب معدل الاستخداه

\begin{tabular}{|c|c|c|c|c|c|}
\hline القيمة الاحتمالية & قيمة ف & متوسط المربعات & درجات الحرية & مجموع المربعات & مصدر التباين \\
\hline \multirow{3}{*}{$\cdots$. } & \multirow{3}{*}{$\xi 1,0 . \xi$} & Irrqar, rAq & $r$ & rroras,ora $\square$ & بين المجموعات \\
\hline & & miqv, 1.r] & vพ⿺ & Tr|sV.1,7ra] & داخل المجموعات \\
\hline & & & rrq] & rOA*A17, riv & الكلى \\
\hline
\end{tabular}

يوضح جدول (0) وجود فروق دالة إحصائياً حسب معدل الاستخدا م حيث بلغت قيمة

(ف) (41.504) وهي قيمة دالة عند مستوى (000.)، ولمعرفة اتجاه هذه الفروق تم تطبيق

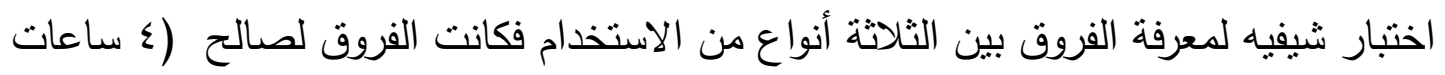

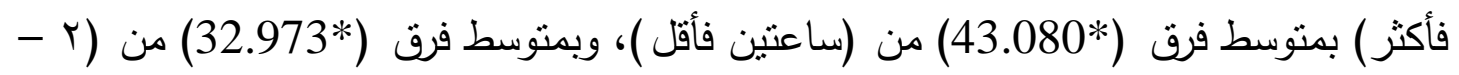

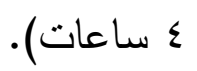

نتيجة السؤال السابع الفروق في إدمان الهواتف الذكية للى طلبة جامعة الخرطوم تبعا للتخصص (علمي/ أدبي)؟ للإجابة عن هذا السؤال تم تطبيق اختبار (ت) لعينتين مستقلتين غير مرتبطنتين، ونتيجة هذا الاجراء كما يلي: جدول رقم (1) الفروق في ادمان الهواتف اللذلية حسب التخصص

\begin{tabular}{|c|c|c|c|c|c|c|}
\hline القيمة الاحتمالية & قيمةت & درجات الحرية & الانحراف المعياري & المتوسط الحسابي & العدد & التخصص \\
\hline \multirow{2}{*}{$. .1]$} & \multirow{2}{*}{ r, rs } & \multirow{2}{*}{ rro } & $0\}$, raq & rIY,\{V】 & ror & علمي \\
\hline & & & $97,\{09 \square$ & rrv, 17] & rro $]$ & أدبي \\
\hline
\end{tabular}


يوضح جدول (†) وجود فروق ذات دلالة إحصائية بين الطلبة الأدبيين والطلبة العلميين في إدمان الهواتف الذكية، حيث بلغت قيمة (ت) (3.344) وهي قيمة دالة إحصائياً عند مستوى (001.) وهذه الفروق لصالح الطلبة الأدبيين.

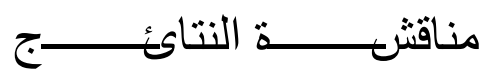

بما أن مجال إدمان الهواتف الذكية من الموضوعات الحديث جداً، والتي لم يتم تتاولها بعمق ولم تجد حظاً جيداً من البحث في السودان، فاتجاه الباحثين نحو تفسير الفروض عموماً تم من خلال الدراسات السابقة لمجتمعات مختلفة.

\section{الفرض الأول : كشفت نتائج الدراسة أن نسبة انتشار إدمان الهواتف الدكية تبلغ (39.2\% ).}

تتسق هذه النتيجة وأدبياتها، وتفسر من خلال المشكلة والأهمية التي طرحتها، وبما أن

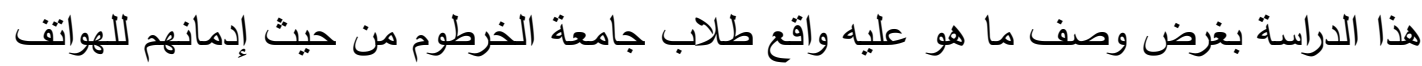

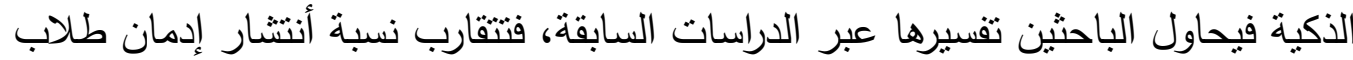

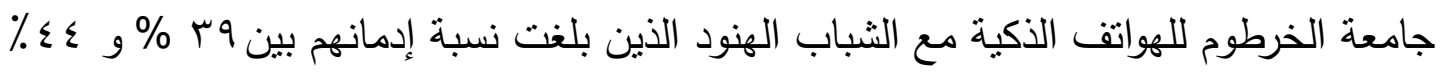

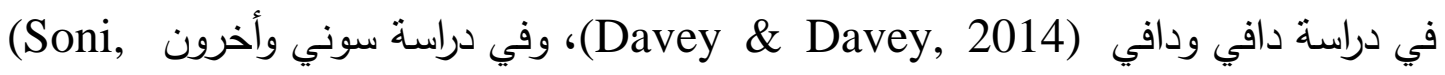

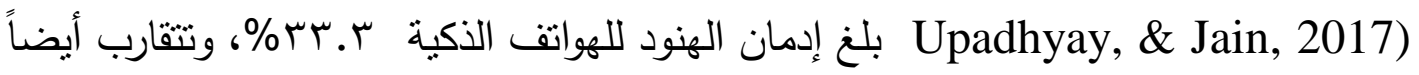

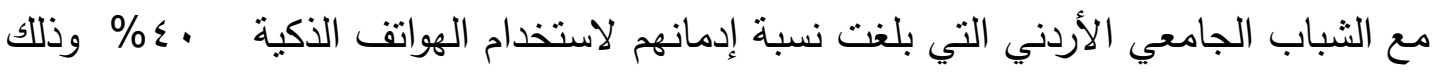
في دراسة جمال وآخرون (2015) Aamal, Alzayyat, \& Ahmed) بينما وجد الفرح

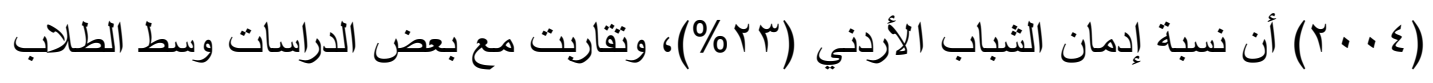

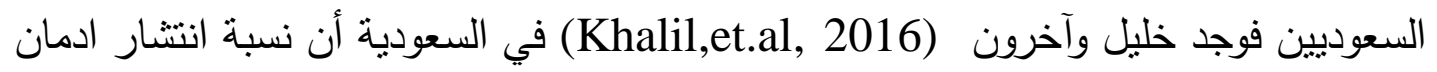

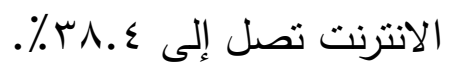

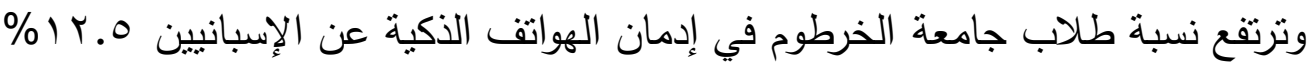

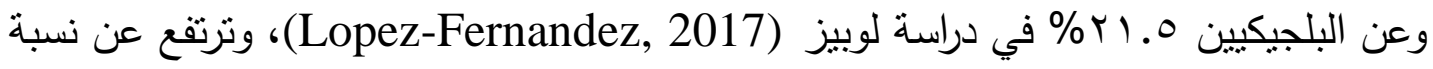

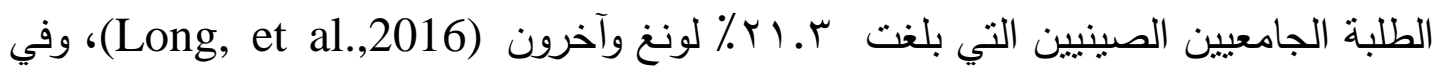

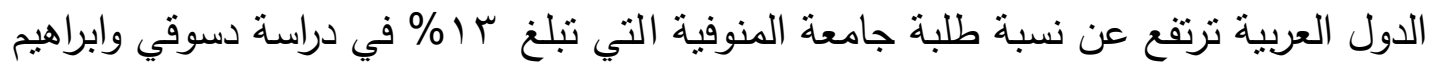
.(Desouky \& Ibrahem, 2015) 
إدمان الهو اتف الذكية لاى طلبا

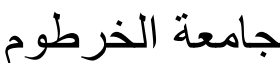

وتقل جداً نسبة طلاب جامعة الخرطوم عن النسب التي كثفت عنها دراسة الثدايفات

وآخرون (Al-Shdayfat, 2016) وسط المراهقين في شمال الأردن الذين تتراوح أعمارهم بين

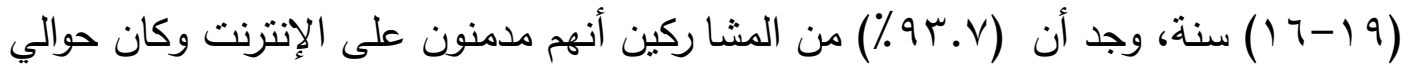

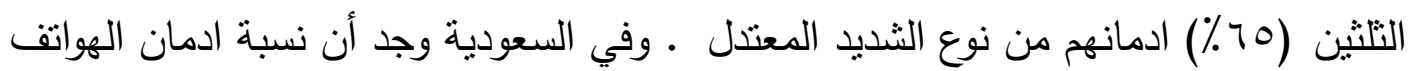

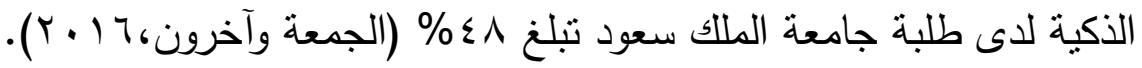

وتقسر هذه النتيجة ما هو عليه الواقع المعاث اليوم، فلا نحتاج إلى م لاحظة علمية دقيقة لنتلمس واقع انتشار إدمان الطلاب للهواتف الذكية ف فبمجرد الملاحظة العرضية العابرة

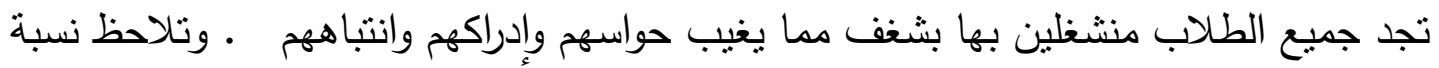

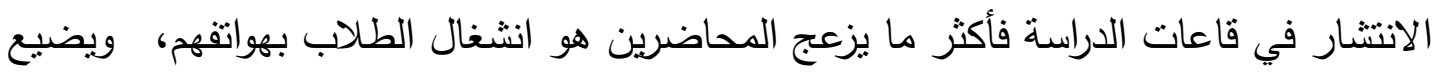
جزء كبير من الوقت في التتبيه على غلق الجوال أو طلب وضعاعه بعيداً ـ وقد يكون انتقال قاعات الدراسة إلى صفوف افتراضية على الإنترنت عزز لدى الطلاب قضاء لفاء أكثر وقتهر

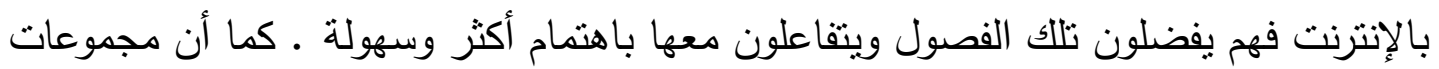
الدراسة والصفحات الاككترونية للأساتذة جعلتهم ينجزون أنشطتهم الدراسية عبر وسائل التواصل الالكتروني، ويستقون معلوماتهم من المواقع البحثية. ومن مشاهدات الباحثين وقضاءهم ساعات

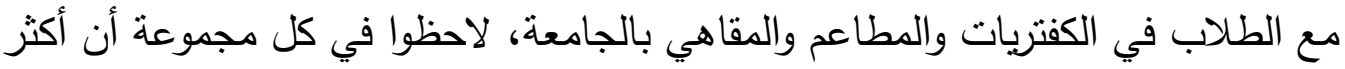

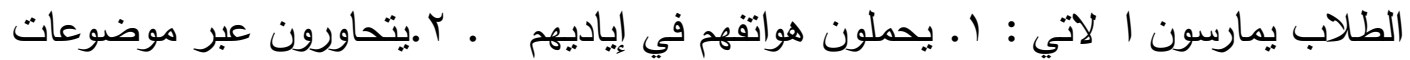

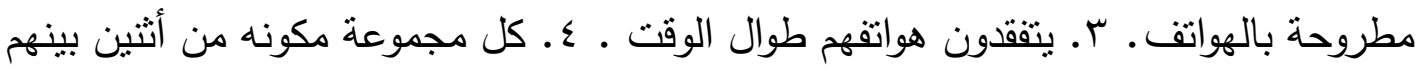

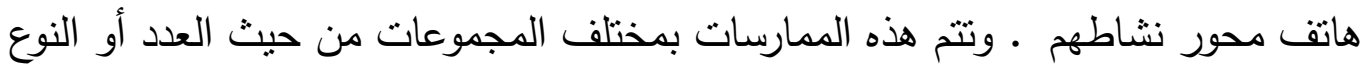
وبمختلف حال الطلاب جالسين واقفين أو يمشهن. واختلفت في مكان واحد وهو مكتبة الجامعة يمنع فيها تعاطي الهواتف الذكية، وبالتالي كان بها عدد قليل جدا من الطلاب ورغم اللوائح

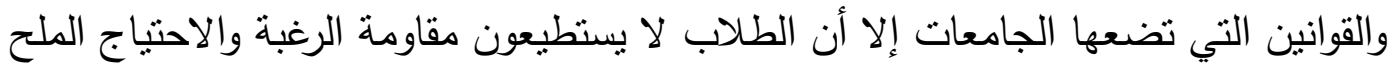

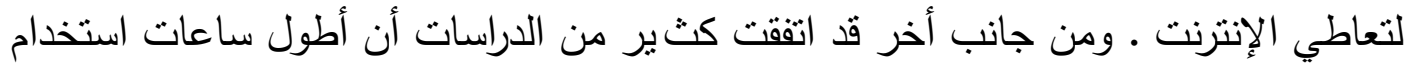

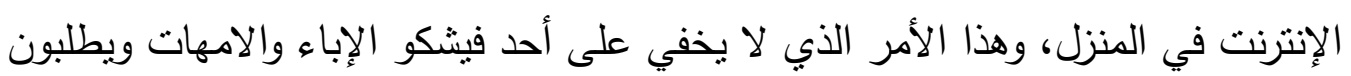

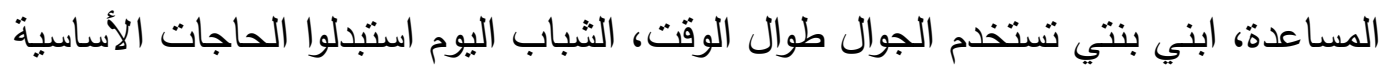

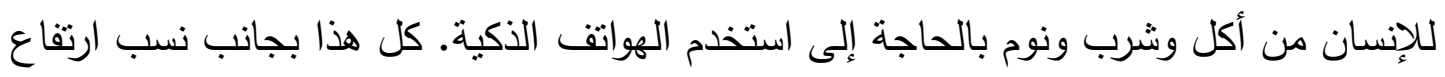


المشكلات الاخلاقية والاعتداءات والخيانات الزوجية وترويج المخدرات والسرقة والاحتيال وحوادث المرور، يفسر ارتفاع نسبة إدمان الطلاب للهواتف الذكية.

\section{الفرض الثاني : علدموجود فروق بين الذكوروالإناث في إدمان الهواتف الذكية}

نال متغيد النوع قدراً كبيراً من التتاول في دراسات ادمان الانترنت والهواتق الذكية،

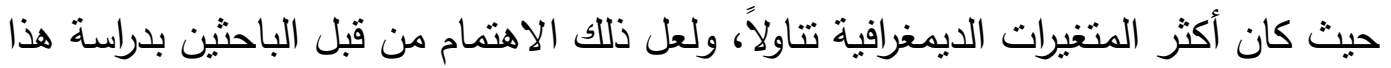

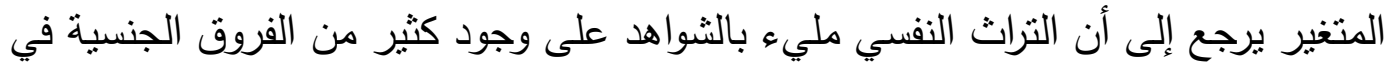
العديد من الظواهر النفسية، ويبين تتبع الفروق الجنسية في إدمان الهواتق الذكية في الدراسات

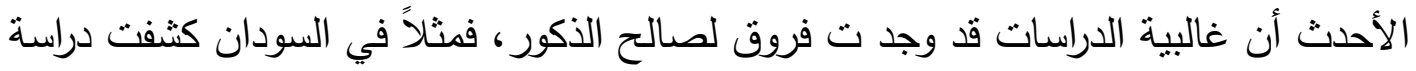

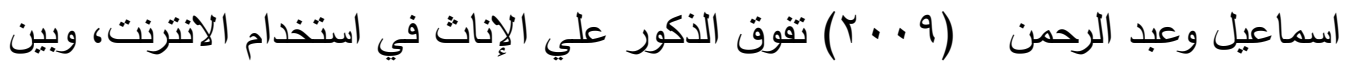

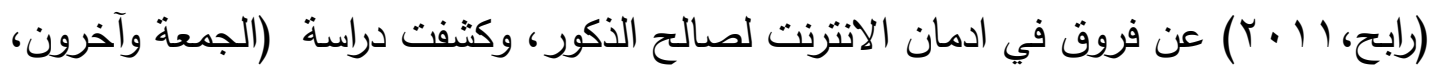

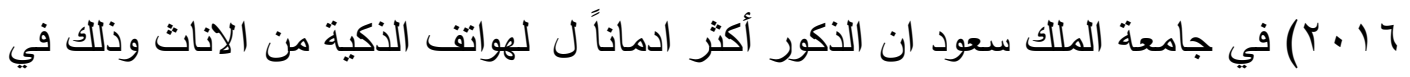

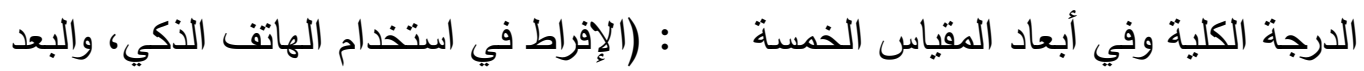

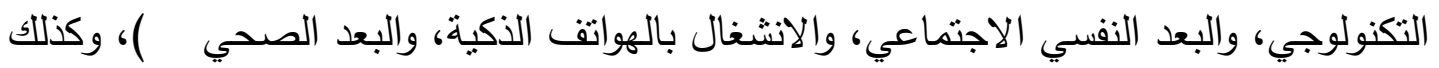
كثفت دراسة بيسين ودشباندي (Bisen \& Deshpande, 2016) وسط ط لاب كليات

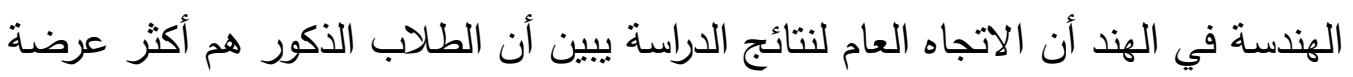

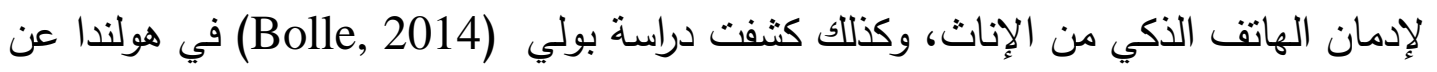

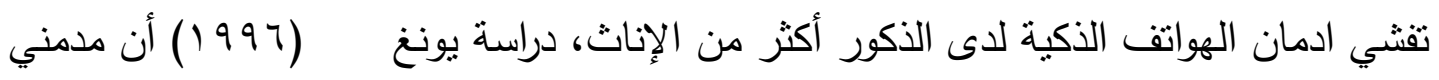

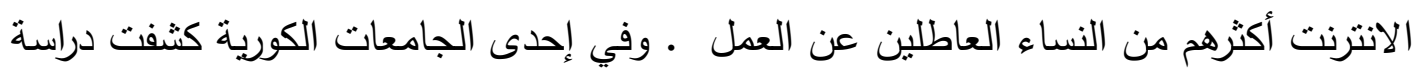
كون وبيك (Kwon \& Paek,2016) أن الطلاب الذكور ينتشر لديهم ادمان الهاتف الذكي

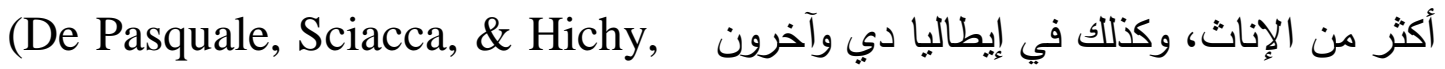
Park \& Lee, 2014a, ينية (2015) (2014b)

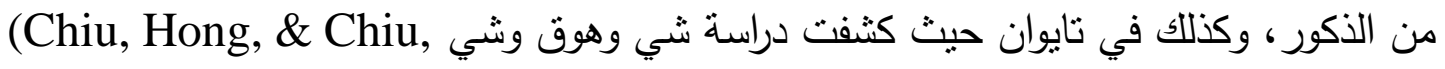

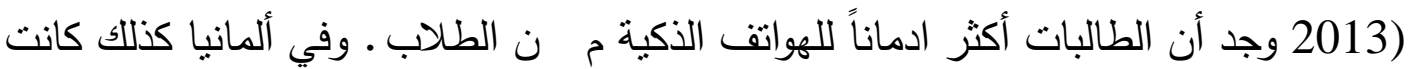
الطالبات أكثر ادماناً للهواتف الذكية من الطلاب راندلر وأخرون (Randler, et al. 2016) ولعل التباين في هذه النتائج الخاصة بالفروق الجنسية يستلزم إجراء دراسات تحليل بعدي رلحرن 
إدمان الهو اتف الذكية لدى طلبا جامعة الخرطوم لأل

Review ( لحسم الأمر ، وفي هذا الاتجاه فقد أجريت در اسة مرجعية (Meta-Analysis) (Study

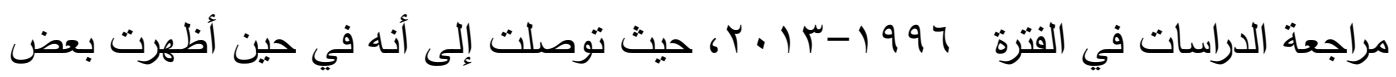

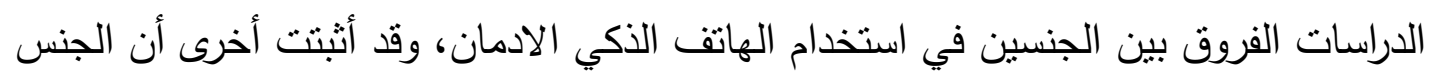

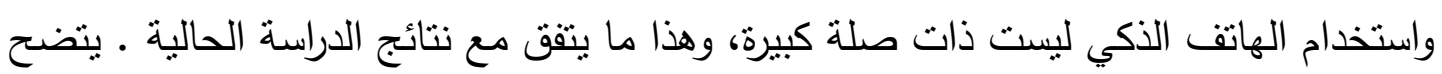

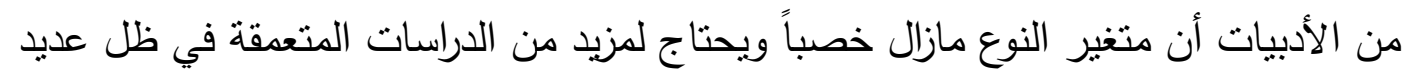

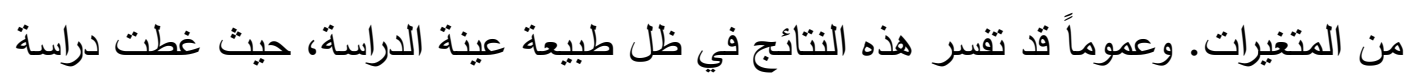

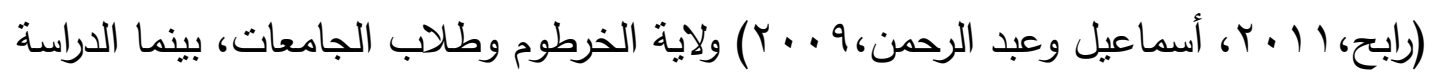

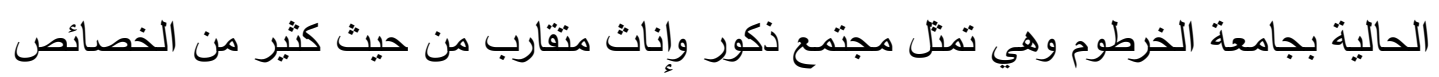

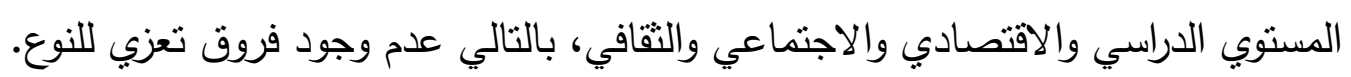

\section{الفرض الثالث : علدم وجود علاقة بين العمر الزمني وإدمان الهواتف الذكية لدى طلبة جامعة}

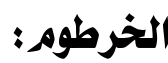

وجد العمر الزمني وعلاقاته بإدمان الانترنت أو إدمان الهواتف الذكية حظاً من الدراسة،

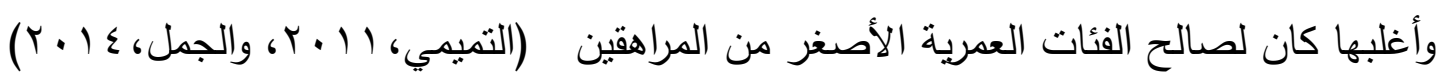

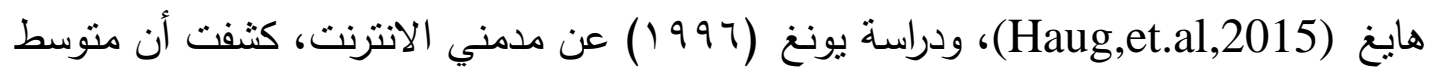

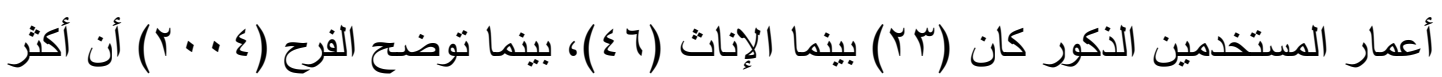

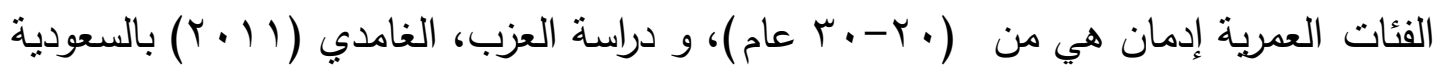

وجدت علاقة ارتباطيه سالبة بين العمر ومعظم أبعاد أنماط الاستخدام منل معدل استخدام غرف الدردشة وملكية جهاز حاسب خاص ما يثير إلى الانخفاض على معظم أبعاد الاستخدام بزيادة المرحلة العمرية للطلاب.

واختلفت الدراسة الحالية مع تللك النتائج، والمثير للاهتمام أنها اتفقت مع دراسة (رابح،

(Y) التي لم تجد فروق حسب العمر الزمني، وقد يعزي هذا الاتفاق للطبيعة النمطية

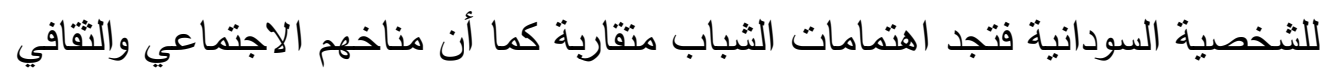

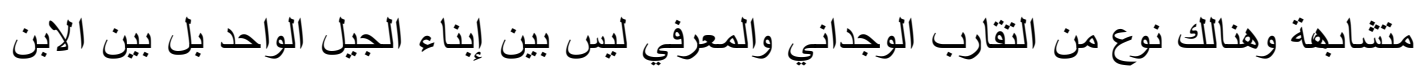

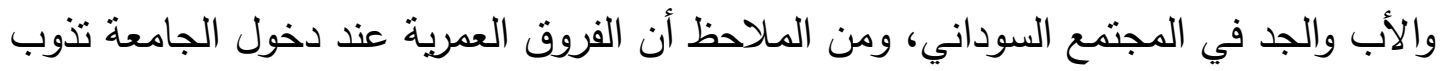


فتتوحد الاهتمامات والمعارف ـ وبما أن المدى العمري متقارب فقد ترتبط الفروقات في العمر عند التفاعل مع متغيرات أخري، منل الفصل الدراسي والمستوي الأكاديمي والنوع وغيرها.

\section{الفرض الرابح : عدم وجود فروق حسب الحالة الاجتماعية (أعزب/متزوج/ أخرى) .}

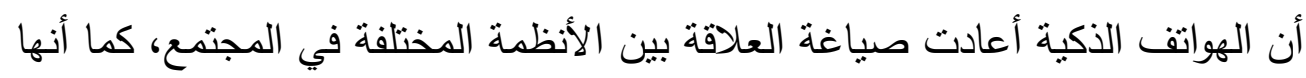

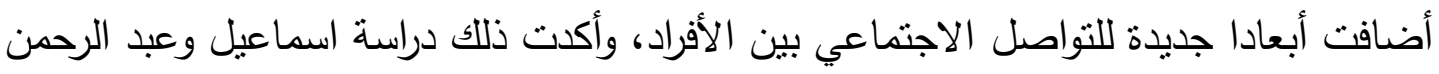

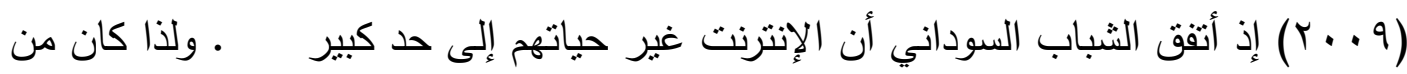

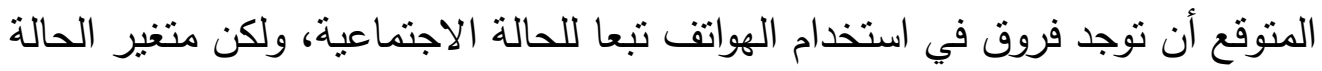

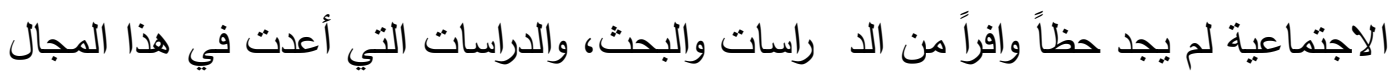

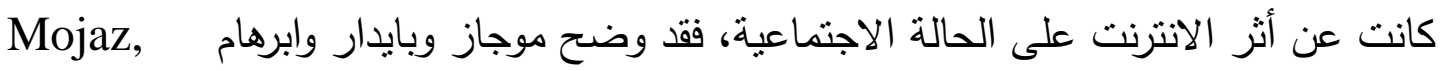
(Paydar, \& Ebrahim, 2015)

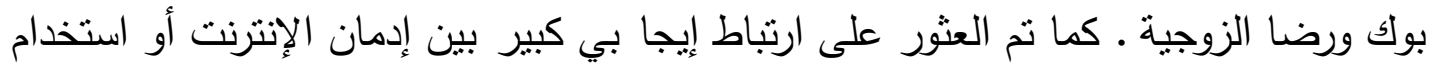

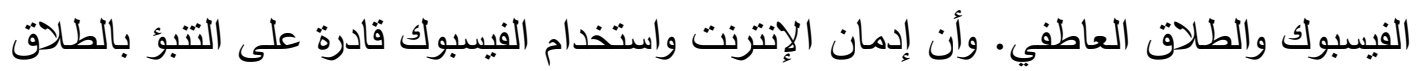

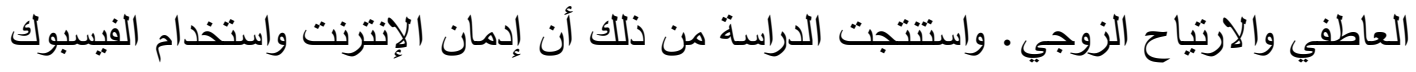

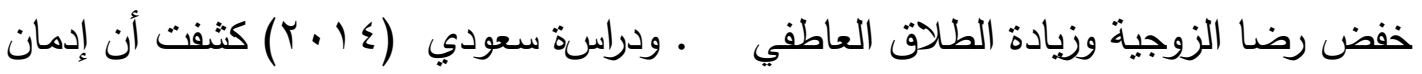
الفيسبوك يؤثر على التوافق الأسري علي الطالب الجامعي.

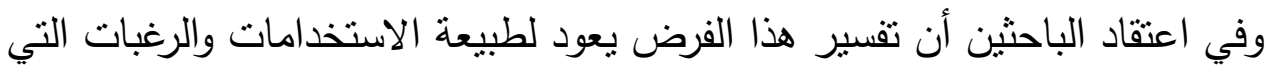

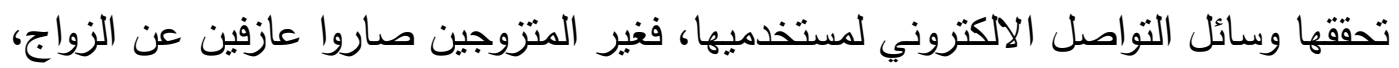

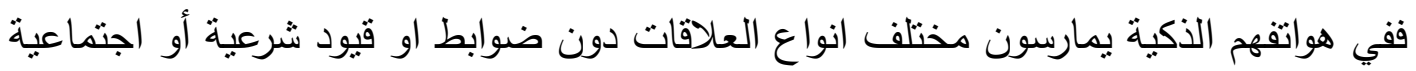

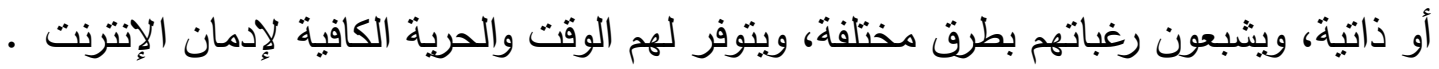

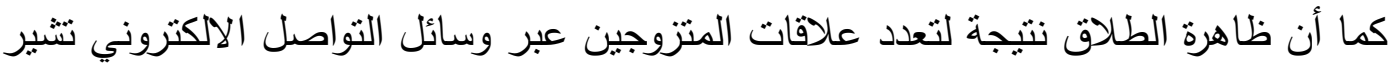

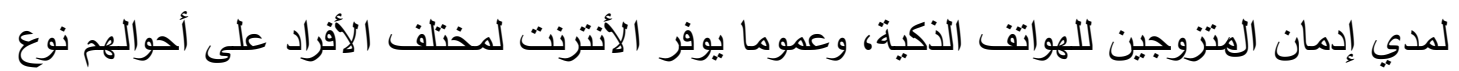

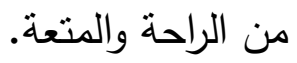


إدمان الهو اتف الذكية لدى طلبا

جامعة الخرطوم لأل

\section{الفرض الخامس : علدم وجود فروق ذات دلالة إحصائية بين طلبة البكالوريوس وطلبة الدراسات}

\section{العليا في إدمان الهواتف الدكية.}

لم تجر دراسات كثيرة للمقارنة بين طلاب البكالوري وس والدان الدواسات العليا في ادمان

الهواتق الذكية، والقليل منها بينت وجود فروق وكانت لصالح طلاب البكالوريوس، وكثفت

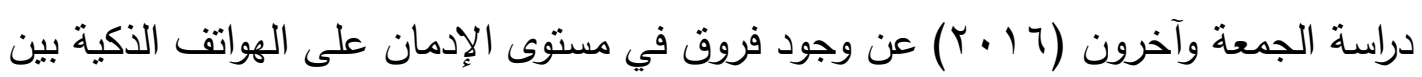

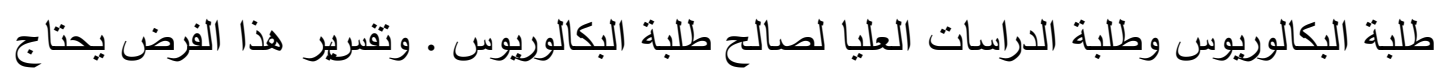
مزيد من الدراسات المتعققة بوجود وتفاعل عديد من المتغيرات، ولكن بصوره عامه يمكن تفسير

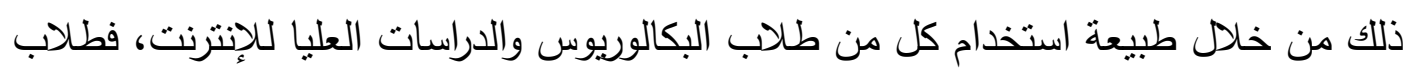
الدراسات العليا أكثر حرصاً على وقتهم، فطبيعة دراستهم بها ضغط أكاديمي عالي ومحددة بفترة

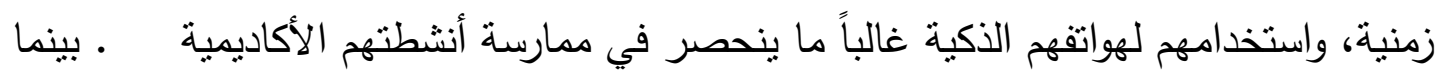

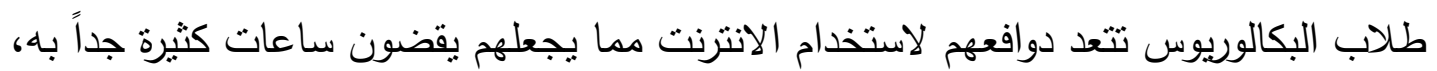

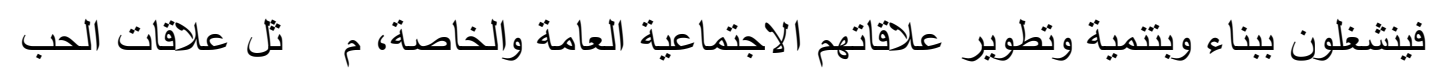

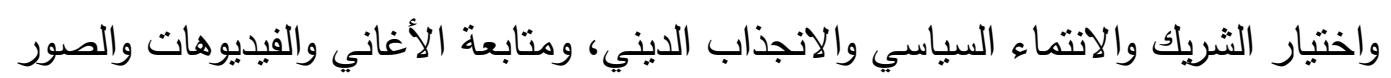

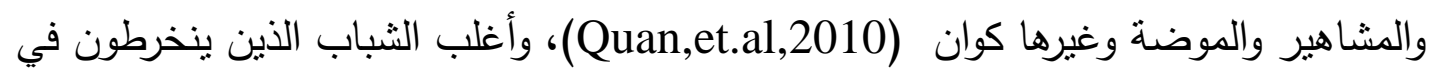

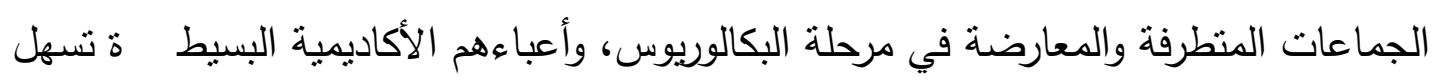
عليهم هذا الأمر.

\section{الفرض السادس : وجود فروق حسب معدل الاستخلام، لصالح (ع ساعات فأكثر ).}

تتتسق نتيجة هذا الفرض وأدبيات البحث، فإدمان الهواتف الذكية هو قضاء ساعات طويلة من الاستخدام، وأكثر الدراسات التي تتاولت الإنترنت بحثت في الاستخدام وتوفر كم جيد إندان

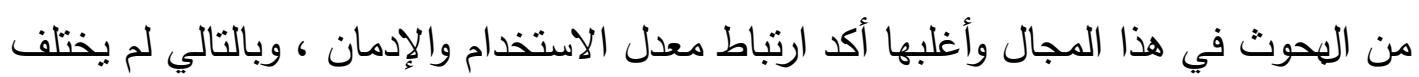

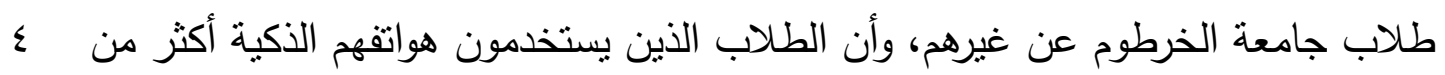

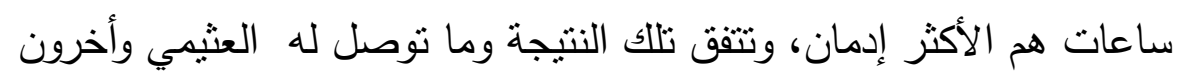
أن (Alosaimi,et.al 2016)

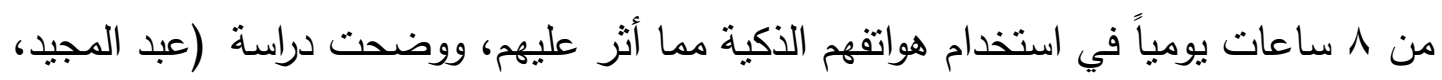




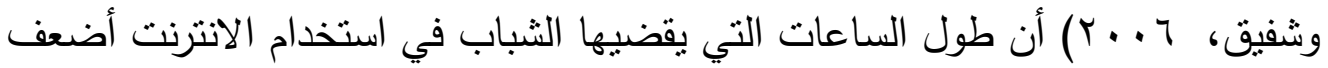

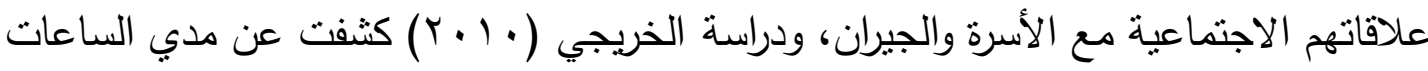

الطويلة التي يقضيها الثباب السعودي بالإنترنت خاصة في الفترة المسائية مما يؤثر على الإنى

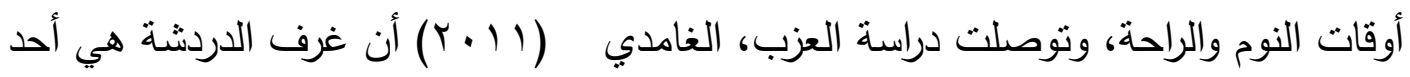
الأساليب الفعالة للتواصل الاجتماعي ومدة استخدامها تتراوح من ساعة إلى أقل من ب ساعات يوميا لدى الجنسين وفترة المساء هي الوقت المفضل للاستخدام • ويفسر هذا الفرض نفسه فهو يوضح أن طول الاستخدام يؤدي الى الإدمان.

\section{الفرض السابع : وجود فروق بين الطلبة الأدبيين والطلبة العلميين في إدمان الهواتف الذكية، وهذه الفروق لصالح الطلبة الأدبيين.}

وجد طلاب الكليات الأدبية حظاً أوفر من الدراسات فهي تتنمي للعلوم الأدبية

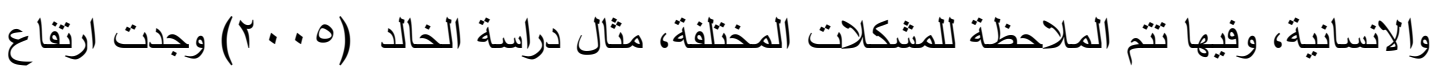
نسبة انتشار استخدام الإنترنت وسط طالبات كلية التربية بجامعة الملك سعود، وقد يكون هذا

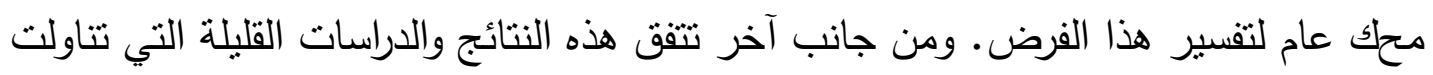
متغير الكلية فقد بينت دراسة التركي (ع ا ب ب) بأن طلاب الكليات الانسانية أكثر استخداما

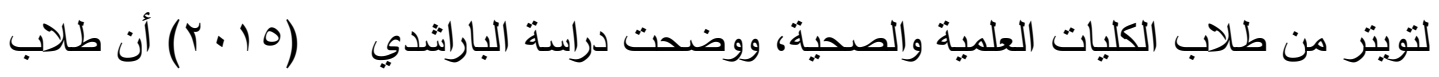

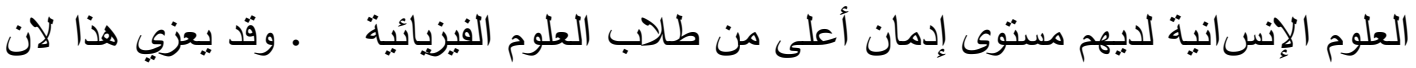

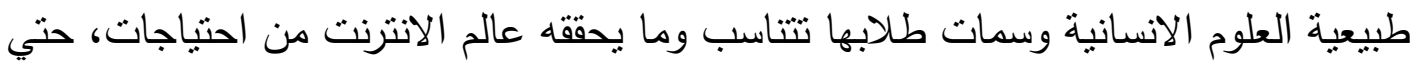

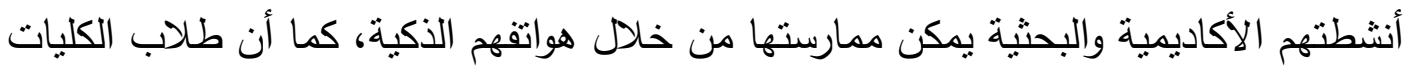

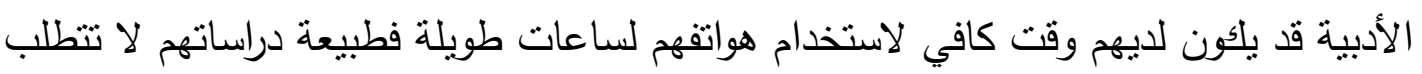
عمل عملي وإرهاق ذهني وضغط أكاديمي بينما طلاب الكليات العلمية دوماً في انشغال أكاديمي وتطبيقات عملية ترهقهم ذهنياً وجسدياً بحيث ما يجدونه من الوقت يحتاجونه للراحة

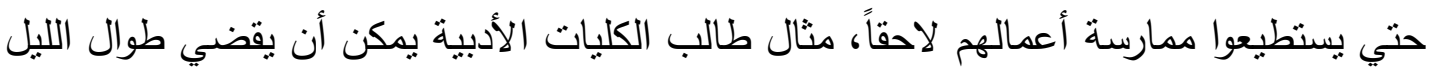

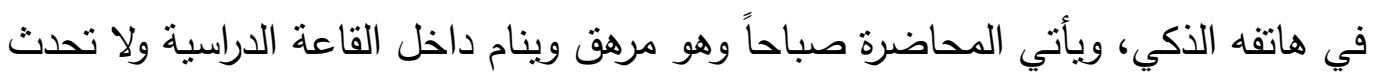

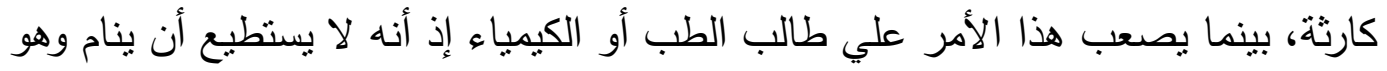

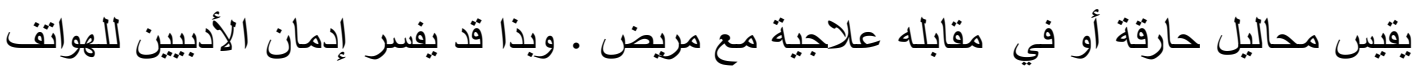

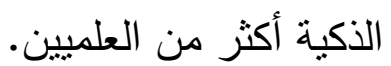


إدمان الهو اتف الذكية لدى طلبا جامعة الخرطوم لأل

يستتتج من الأدبيات السابقة والدراسة الميدانية خطورة ظاهرة ادمان الهواتف الذكية لدى الهى

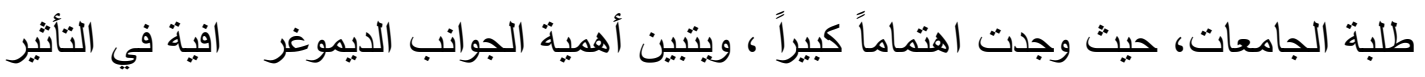

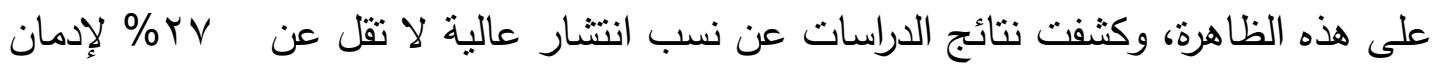

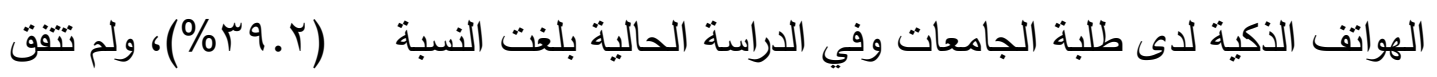

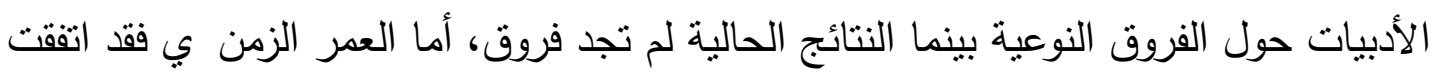

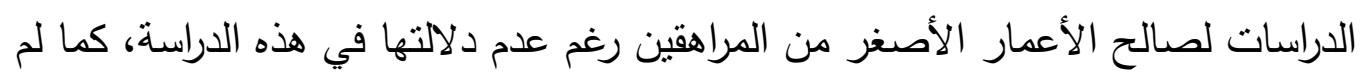

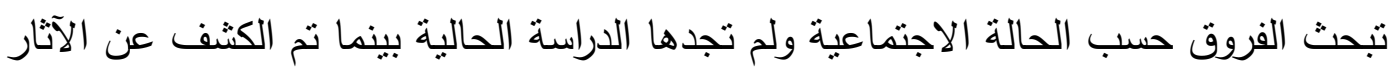

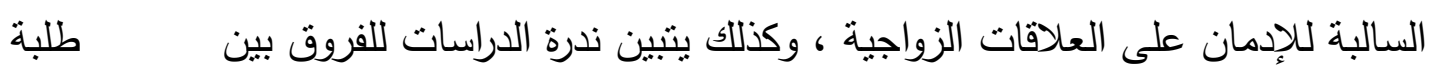

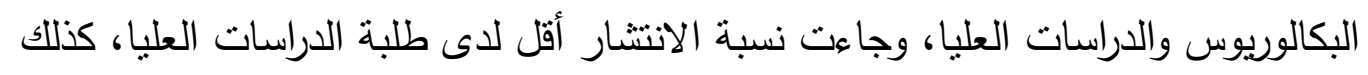

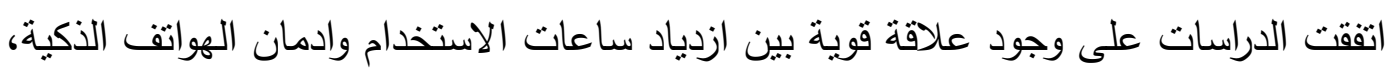

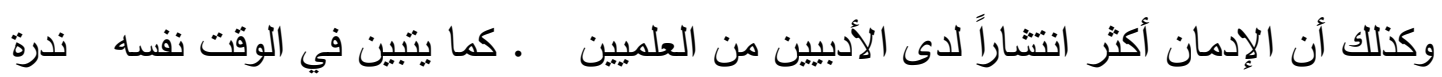

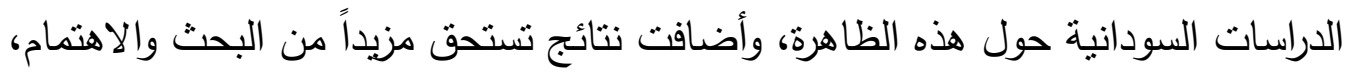
وخرجت ببعض التوصيات.

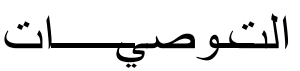
ا خرورة أن تبذل المؤسسات المسئولة من الثباب (الأسرة، الجامعة، الدولة، المجتمع) مزيداً

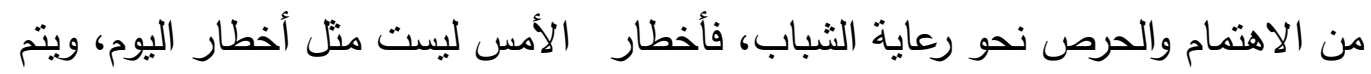

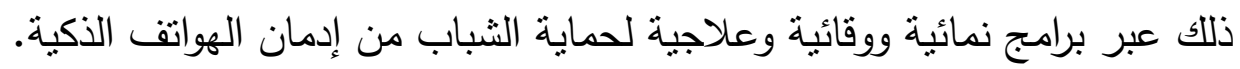

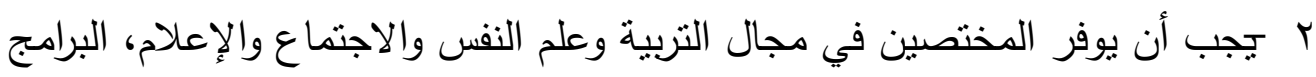
ي

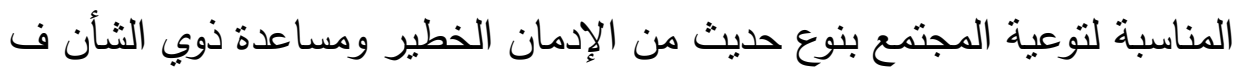

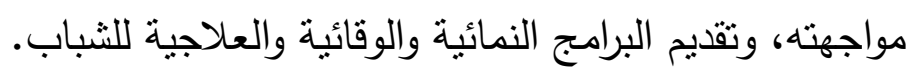

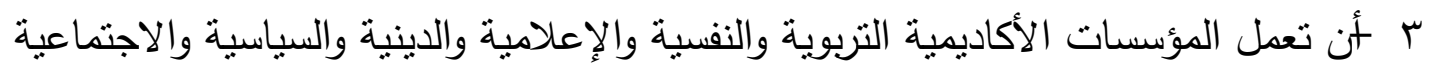

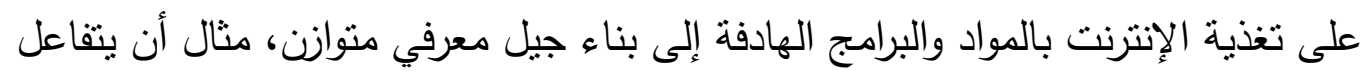

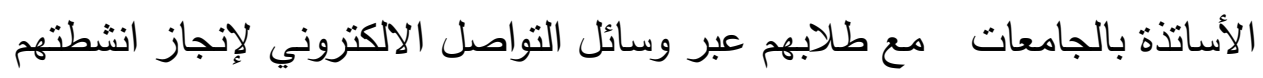

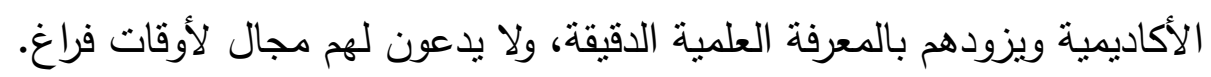


ع أهمية أن يزيد الإباء والأمهات من ثقافتهم الإلكترونية، حتى يستطيعوا مشاركة الأبناء

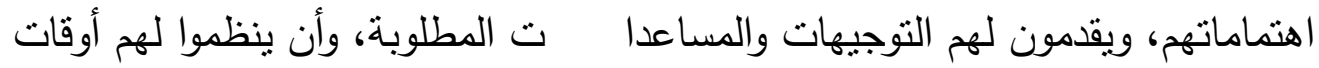
استخدامهم للهواتق الذكية. ه ضرورة أثراء البرامج الأكاديمية بالنسبة لطلاب الكليات الأدبية، وأن تصاحب الدراسات

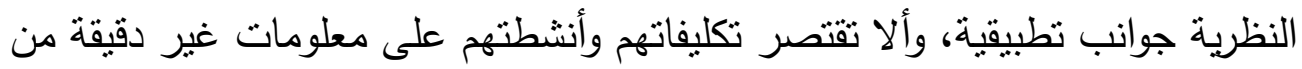
الأنترنت بل تخضع للتجريب والواقع العملي. 7

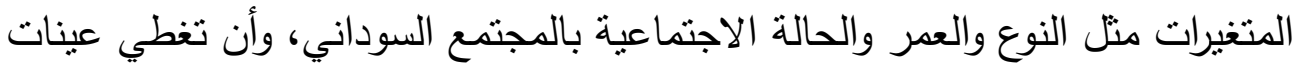
مختلفة منل طلاب الدراسات العليا والمتزوجين وغير المتزوجين وطلاب الكليات العلمية الصحية والهندسية والفنية.

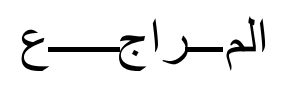

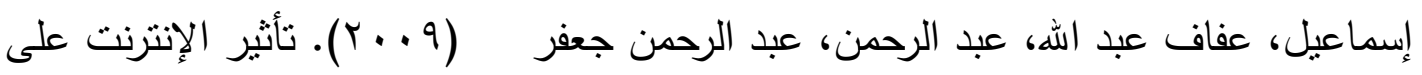

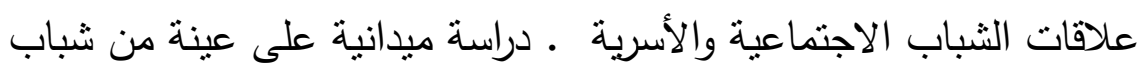

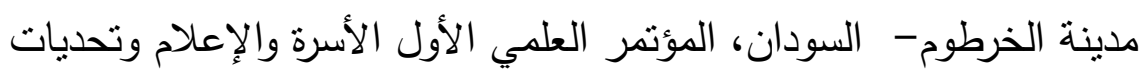

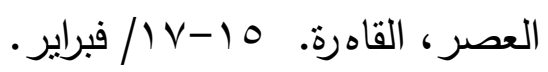

التركي، عثمان تركي (ع ( ب ). دوافع استخدام طلبة وطالبات جامعة الملك سعود للتويتز وآثاره على العملية التعليمية. دراسات عربية في التربية وعلم النفس، 7 ؛(r). التميمي، عبد الله (11 ـ ب). الأسباب الكامنة وراء انتثار أجهزة البلاك بيري والآثار التز بوية المترتبة على ذلك من وجهة نظر طلبة المرحلة الثانوية في منطقة أبو ظبي لبني التعليمية، ورقة عمل في مؤتمر مخاطر الجهاز النقال على طلبة المرحلة

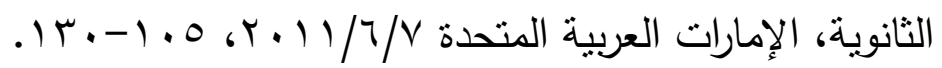
الجمل، سمير (ع ( ب). الآثار السلبية للهواتف الذكية على سلوكيات ا لطلبة من وجهة نظر المرشدين ومديري المدارس في جنوب الخليل، مجلة جامعة القس المفتوحة

$$
.9 \cdot-7 \cdot 6(\text {. ( ) r) } \leqslant \text { ، }
$$


إدمان الهو اتف الذكية لاى طلبا جامعة الخرطوم لألفي

الخريجي، فهد بن عبد العزيز (• • ( ). استخدامات طلاب قسم الإعلام بجامعة المك سعود لثبكة الإنترنت والإثباعات المتحققة دراسة ميدانية ـ مجلة الآداب جامعة

$$
\text { الملك سعود، الرياض.r. r (1).0.0 - } 90 .
$$

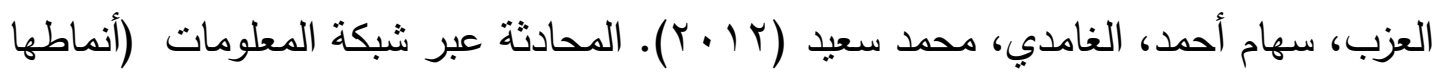
ودوافعها وآثارها ) دراسة ميدانية على طلاب جامعة الملك عبد العزيز مجلة

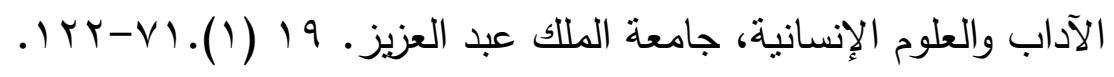

حافظ، عبده (1 ( • ץ). تواصل الثباب الجامعي من خلال الثبكات الاجتماعينألمؤتمر العلمي-

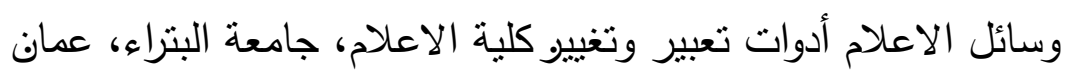

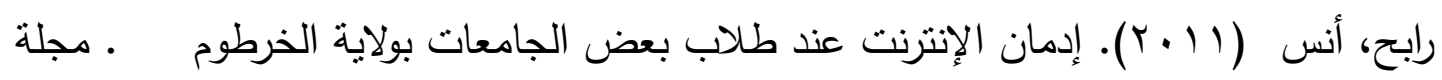

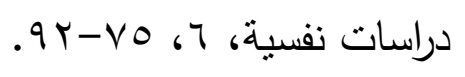

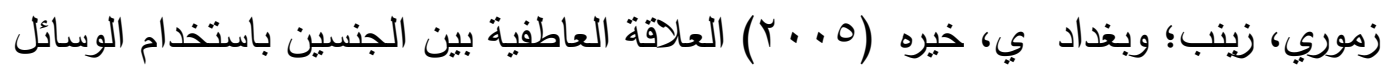
الإلكترونية بين المجتمع الافتراضي والمجتمع الحقيقي، مجلة العلوم الانسانية

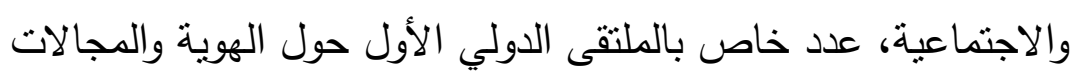
الاجتماعية في ظل التحولات السوسيوثقافية في المجتمع الجزائي.

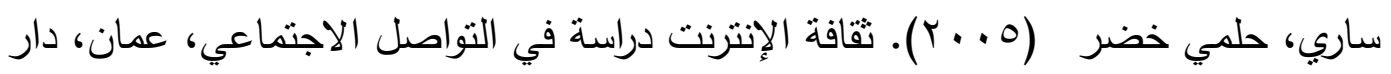
مجدلاوي للنشر والتوزيع.

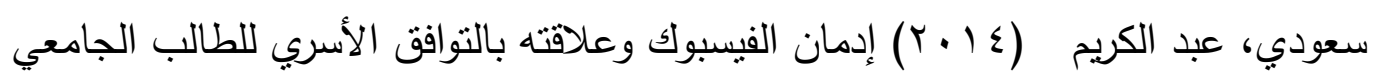

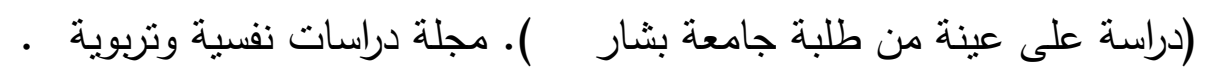

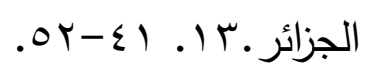

عبد المجيد، محمد سعيد؛ شفيق، وجدي (T . . r) الآثار الاجتماعية للإنترنت على الثباب . دراسة ميدانية على عينة من المترددين على مقاهي الإنترنت في مدينة طنطا .

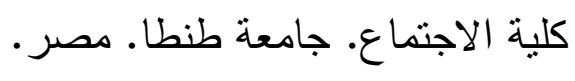




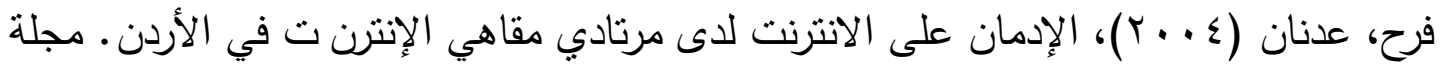

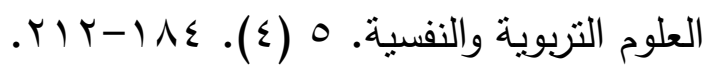

فوزي، أحمد سعيد. (1 . . r). أهم المشكلات النفسية والاجتماعية الناجمة عن إدمان المراهقين

للإنترنت . رسالة ماجستير غير منشورة ـ قسم الدراسات النفسية والاجتماعية . معهد الدراسات العليا للطفولة. جامعة عين شعس.

منصور ، تحسين (؟ + ץ) استخدام الإنترنت ودوافعها لدى طلبة جامعة البحرين. المجلة العربية

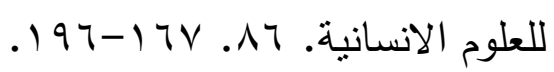

Alasdair, A \& Philips, J. (2011) Children and Mobile Phones, the content of this Article can be freely used with appropriate citation www.powerwatch.org.uk.or www.emfields.org. P1-8.

Al-Barashdi,H., Bouazza, A., \& Jabur, N.(2015). Smartphone Addiction among University Undergraduates: A Literature Review. Journal of Scientific Research \& Reports,4(3), 210-225.

Aljomaa,S; Al.Qudah, M; Albursan, I; Bakhiet,S; \& Abduljabbar, A. (2016).Smartphone addiction among university students in the light of some variables. Computers in Human Behavior, 61, 155-164.

Alosaimi, F., Alyahya, H.; Alshahwan, H.; Al Mahyijari, N.; \& Shaik, S. (2016). Smartphone addiction among university students in Riyadh, Saudi Arabia. Saudi Medical Journal, 37(6), 675683.

Al-Shdayfat, N., Hawi, N., Hamadneh,S., Albnian, F., Alzyoud, S., \& Logue, T.(2016). Internet Addiction among School Adolescents in Northeastern Jordan. World Journal of Medical Sciences, 13 (4), 218-224.

Bisen, S; Deshpande, Y. (2016). An Analytical Study of Smartphone Addiction among Engineering Students: A Gender 
إدمان الهو اتف الذكية لدى طلب

جامعة الخر طوم لألة طل

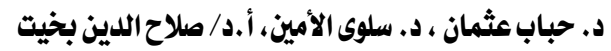

Differences. The International Journal of Indian Psychology, 4(1), 70-83.

Bolle, C. (2014). "Who is a smartphone addict?" The impact of personal factors and type of usage on smartphone addiction in a Dutch population. Master's thesis, University of Twente Enscheda: Netherlands.

Chen, Y. \& Lever, K. (2004). Relationships among mobile phones, social network and academic achievement: A Comparison of US and Taiwanese College Students, School of Communication, Information, and Library Studies, dissertation abstract.

Chiu, S., Hong, F., \& Chiu, S.(2013). An Analysis on the Correlation and Gender Difference between College Students' Internet Addiction and Mobile Phone Addiction in Taiwan. International Scholarly Research Notices, 2013, (360607), 10

Choi, N.(2015). The Effects of a Smartphone Addiction Education Program for Young Adult Females. International Journal of u- and e- Service, Science and Technology, 8(12), 277-284.

Choi, Y., Koo, J., \& Kim, E.(2015). Gender Differences in Addictive Smartphone Use among Korean Adolescents. Korean Sociology, 12, 143-160.

Davey, S., \& Davey, A.(2014). Assessment of Smartphone Addiction in Indian Adolescents: A Mixed Method Study by Systematicreview and Meta-Analysis Approach. International Journal of Preventive Medicine, 5(12), 1500-1511.

De Pasquale, C., Sciacca, F., \& Hichy, Z.(2015). Smartphone Addiction and Dissociative Experience: An investigation in Italian adolescents aged between 14 and 19 years. International Journal of Psychology \& Behavior Analysis, 109 (1). 


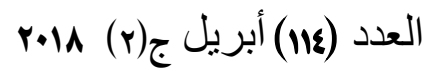

Desouky, D., Ibrahem, R.(2015).Internet Addiction and Psychological Morbidity among Menoufia University Students, Egypt. American Journal of Public Health Research, 3(5), 192-198.

DSM-5.(2013). Diagnostic and Statistical Manual for Mental Disorders -5 th version (DSM-5).

Emanuel, R., Bell, R., Cotton, C., Craig, J., Drummond, D., Gibson, S., Harris, A., Harris, M., Hatcher-V., Jones, S., Lewis, J., Longmire, T., Nash, B., Ryans, T., Tyre, E., Walters, D., Williams, A. (2015). The truth about smartphone addiction. College Student Journal, 49 (2), p291-299. 61.

Gamal, A., Alzayyat, M., \& Ahmed, S. (2015). Prevalence of Internet Addiction and Its Association with Psychological Distress and Coping Strategies Among University Students in Jordan. Perspectives in Psychiatric Care, 52(1). 49-61.

Goodman, A. (1990). Addiction: Definition and implications. British Journal of Addiction, 85(11), 1403-1408.

Griffiths, M. (2000). Does Internet and computer "addiction" exist? Some case study evidence. Cyber Psychology \& Behavior, $3(2), 211-218$.

Haug, S., Castro, R., Kwon, M., Filler, A , Kowatsch, T., \& Schaub, M.(2015). Smartphone use and smartphone addiction among young people in Switzerland. JOURNAL OF Behavioral Addiction, 4(4): 299-307.

Hawi, N. ; Samaha, M.(2016).To excel or not to excel: Strong evidence on the adverse effect of smartphone addiction on academic performance. Computers \& Education, 98, 81-89. doi.org/10.1016/j.compedu.2016.03.007

Hong, F.; Chiu, S.; \& Huang, D.(2012). A model of the relationship between psychological characteristics, mobile phone addiction and use of mobile phones by Taiwanese university female students. Computers in Human Behavior, 28(6), 2152-2159.

http://www.psychiatry.org/practice/dsm/dsm5. 
إدمان الهو اتف الذكية لدى طلب

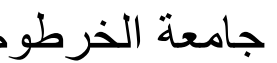

Khalil, A., Alharbi, N., Alhawasawi, H., Albander, A.(2016). Prevalence of Internet Addiction among Nursing Students and the Association with their Academic Performance and Mental Health. Athens Journal of Health, 3(4), 291-306.

Kim, Y.; Lee, N.;\& Lim, Y.(2017). Gender differences in the association of smartphone addiction with food group consumption among Korean adolescents. Public Health, $145,132-135$.

Korea Diverse Dimensions of Smartphone Use and Individual Traits. Communications and Information Studies, 51(1), 2014, 100-132.

Kwon, Y., Paek, K.(2016). The Influence of Smartphone Addiction on Depression and Communication Competence among College Students. Indian Journal of Science and Technology, 9(41),1-8.

Long, J.,Liu, T., Liao, Y., Qi, C., He, H., Chen, S., \& Billieux, J.(2016).

Prevalence and correlates of problematic smartphone use in a large random sample of Chinese undergraduates. BMC Psychiatry, 16, 408-420. DOI: 10.1186/s12888-016-1083-3

Lopez-Fernandez, O.(2017). Short version of the Smartphone Addiction Scale adapted to Spanish and French: Towards a crosscultural research in problematic mobile phone use. Addictive behaviors, 64, 275-280. Doi: https://doi.org/10.1016/j.addbeh.2015.11.013

Mojaz, Z., Paydar, M., \& Ebrahim, M.(2015). The relationship between the internet addiction and the use of Facebook with marital satisfaction and emotional divorce among married university student. Indian Journal of Fundamental and Applied Life Sciences, 5(3), 709-717.

Okwaraji, F., Aguwa, E., Onyebueke, G., Arinze-Onyia, S., \& ShiweobiEze, C.(2015). Gender, Age and Class in School Differences in Internet Addiction and Psychological Distress among Adolescents in a Nigerian Urban City. 


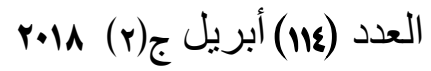

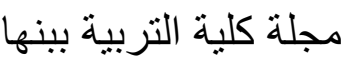

International Neuropsychiatric Disease Journal,4(3), 123131. DOI : 10.9734/INDJ/2015/18933

Olufadi, Y., (2015). Configurationally approach to the investigation of the multiple paths to success of students through mobile phone use behaviors. Computers, 86, 84- 104.

Park, N., \& Lee, H.(2014a). Gender Difference in Social Networking on Smartphones: A Case Study of Korean College Student Smartphone Users. International Telecommunications Policy Review, 21 (2), 1-18.

Park, N., \& Lee, H.(2014b). Nature of Youth Smartphone Addiction in Quan, Haase, Anabel; Young, Alyson L(2010). Uses and Gratifications of Social Media: A Comparison of Facebook and Instant Messaging, Bulletin of Science, Technology \& Society, 30 (5) Oct.

Randler, C; Wolfgang,L; Matt, K; Demirhan,E; Bari,M; Horzoum; S, \& Soluk,S (2016). Smartphone addiction proneness in relation to sleep and morning ness-evening ness in German adolescents. Journal of Behavioral Addictions, 5(3), 465-473.

Seo, D., Park, Y.; Kim, M.; \& Park, J.(2016). Mobile phone dependency and its impacts on adolescents' social and academic behaviors. Computers in Human Behavior, 63, 282-292.

Soni, R., Upadhyay, R.,\& Jain, M.(2017). Prevalence of smart phone addiction, sleep quality and associated behavior problems in adolescents. International Journal of Research in Medical Sciences, 5 (2), 515-519.

Vansoon,M.(2010) Facebook and the invasion of technological communities , N.Y,Newyurk.

Walsh, S. P., White, K. M., \& Young, R. M. (2008). Over-connected? A qualitative exploration of the relationship between 
إدمان الهو اتف الذكية لدى طلبن جامعة الخرطوم لأل

Australian youth and their mobile phones. Journal of Adolescence, 31, 77 - 92.

Young, K. (1996). Internet addiction: the emergence of new clinical disorder. Paper presented at the 104th annual meeting of psychological association., Toronto , Canada , August 15,1996 . 


\section{Abstract}

Reports had revealed that internet addiction \& smartphone addiction is a newly emerging mental health issue among the youths and has attracted much attention around the world. Furthermore, excessive use of the internet has negatively affected the daily life routines of adolescents \& university students. This phenomenon has also been observed in several Arab and African countries but has not received adequate attention in Sudan. So, the objective of this study was to investigate the phenomenon of smart phone addiction among Khartoum University students, and to identify its relationship with some demographic variables. In order to achieve the objectives of the study, the Arab Smartphone Addiction Scale was administered to (727) males and females students at the University of Khartoum (379) females, and 348 males, ranging in age from 17-30 years, with an average age of (21.47) from scientific and humanities colleges, bachelor and postgraduate students. The results of the study revealed that the prevalence of smart phone addiction is $39.2 \%$, that there are no differences between males and females in the addiction of smart phones, and there is no correlation between age and smart phones addiction. The study also did not reveal differences due to the different social situation, moreover the study did not reveal differences due to differences in the academic stage between bachelor and postgraduate students, while it found differences in smartphones addiction attributed to the difference in the number of hours and the rate of use for those who use the smartphone more than 4 hours a day, and found differences due to the difference of specialization between the humanities students and scientific students in favor of humanities students.

Key words: Smart phone addiction, Sudan, University of Khartoum, sexual differences, prevalence. 